\title{
EFEITOS DA LESÃO TÉRMICA CORPORAL NA MUCOSA E NOS COMPONENTES DO PLEXO MIOENTÉRICO DO ESTÔMAGO DE RATOS
}

Dissertação apresentada ao Instituto de Ciências Biomédicas da Universidade de São Paulo, para obtenção do Título de Mestre em Ciências Morfofuncionais. 
PAULO ALEXANDRE GALVANINI

\section{EFEITOS DA LESÃO TÉRMICA CORPORAL NA MUCOSA E NOS COMPONENTES DO PLEXO MIOENTÉRICO DO ESTÔMAGO DE RATOS}

Dissertação apresentada ao Instituto de Ciências Biomédicas da Universidade de São

Paulo, para obtenção do Título de Mestre em Ciências.

Área de Concentração: Ciências Morfofuncionais

Orientador: Prof. Dr. Edson Aparecido Liberti 
Dedico aos meus pais, um exemplo de retidão, competência e carinho, meus irmãos pelo apoio e companheirismo, e a minha esposa, pelo carinho, incentivo e compreensão. 


\section{AGRADECIMENTOS}

A Deus...

Obrigado meu Deus, por me mostrar que tudo é possível, por não me deixar e nem de desamparar, por me perdoar e estar comigo, por guiar meus passos, por me amar.

\section{A minha família...}

Primeiramente quero agradecer meus pais Odair Galvanini e Maria Santina D. Galvanini, pela compreensão, paciência e amor em todos esses anos, e por sempre acreditarem em mim e me apoiarem, vocês são fundamentais na minha vida. Amo vocês.

Agradeço aos meus irmãos Vander A. Galvanini e Gustavo Galvanini, pelo companheirismo, alegria, apoio e por toda força que me deram, obrigado por vocês existirem na minha vida.

Agradeço à minha esposa Cláudia $S$. Schubert, sem a sua presença me apoiando e acalmando, sem seu carinho me incentivando, sem seu amor me fortalecendo seria impossível este trabalho ter acontecido. Obrigado, você é um presente de Deus na minha vida.

Que Deus os recompense por tanto terem feito por mim.

\section{Aos meus familiares...}

Às minhas cunhadas Keyla Franzin C. Galvanini pelo acolhimento, amor e amizade e Viviane Cantagali, pelo carinho e apoio.

À minha cunhada Gelbi R. Schubert pela amizade, atenção e apoio.

Quero agradecer a todos os meus tios, que direta ou indiretamente, pela presença ou por orações sempre me incentivaram, agradeço especialmente à minha tia Sebastiana Delmonico, pois além de ser um exemplo de vida, sempre esteve ao meu lado em oração, mesmo quando estávamos distantes. 
Agradeço aos meus primos Carlos e Renata Salazar, Gleice Galvanini, Rafael Galvanini e Tia Francisca pela amizade, apoio e presença em todos esses anos.

Obrigado aos meus primos Patrícia Delmonico e Eduardo Luis Delmonico, pela amizade e carinho, e também à tia Neide e tio Luís, por tanto amor por mim demonstrado.

\section{Ao meu orientador...}

Prof. Dr. Edson Aparecido Liberti, por todo acolhimento, ajuda e conselho, pois ser mestre não é apenas lecionar, mas sim ser humano e amigo, guia e companheiro, exemplo de dedicação e doação, de dignidade pessoal e, sobretudo de amor. Muito obrigado pela orientação.

Aos professores...

Agradeço à Prof. Dra. Silvia Boldrini, por sempre estar com seu jeito sereno, ensinando a humildade, retidão, dedicação, brandura, enfim, você é uma pessoa muito especial.

Ao Prof. Dr. Marcílio Hubner de Miranda Neto, à Profa. Dra. Sonia Lucy Molinari e à Profa. Dra. Raquel Marçal Natali que desde o início de minha vida acadêmica, não mediram esforços para me auxiliar.

Ao Prof. Dr. Newton Canteras, coordenador do programa de pós-graduação em Ciências Morfofuncionais e ao Prof. Dr. Jackson C. Bittencourt, chefe do departamento de Anatomia Humana.

\section{Aos meus amigos...}

Ao amigo Carlos Eduardo Seyfert, seu auxilio na pesquisa foi fundamental.

Aos queridos colegas do Laboratório de Anatomia Funcional Aplicado à Clínica e Cirurgia Ágatha Pawlowski de Oliveira, Aline Gonçalves, Allan Benedito 
Bonani, Bruna Cecília Caixeta de Oliveira, Cibele Maciel de Miranda, Diana Alves de Oliveira, Dorival, Terra Martini, Flávia de Oliveira, Isabela de Ugo Luques, Leonardo F. Liberti, Letícia Nogueira da Gama de Souza, Lynda Tamayo Arango, Lucilene Ferreira Luiz, Luiz Henrique Silveira Rodrigues, Marcelo Arthur Cavalli, Marcelo Ferreira Calderon, Márcio Cristófaro, Maritza Alves de Sousa Coura, Mateus Elias Pacheco, Milton de Siqueira Ferreira Anzaloni Saavedra, Paulo Henrique de Matos Alves, Regina de Sousa Bolina, Ricardo, B. V. Fontes, Rogério Cruz de Oliveira, Sabrina Caixeta de Oliveira, Simone Piccoli, Thiago Habacuque Silva Souza, Ticiana Sidorenko de Oliveira Capote, Valquíria Barboza Mariotti, Vânia G. Furlani, Willian Grassi Bautz, pelo excelente convívio, ajuda e suporte não somente nesta pesquisa.

À Maria Teresa Jordão (Plu), Fabrício e Maria Eduarda, pelo acolhimento, aconselhamento e força, obrigado por tudo que vocês fizeram por mim.

À amiga Pamella Faby da Silva, pelo apoio dado na pesquisa, meu muito obrigado.

Aos meus grandes e inesquecíveis amigos do Colégio São João Gualberto, meu muito obrigado, pelo apoio e incentivo.

Aos amigos Kelly Polito, Serginho, Michele Polito, Benedita Polito, Gilberto Polito, Tatiana e Xavier Chable, Lídia e Fátima, pelo acolhimento, apoio, oração, enfim, vocês são muito especiais.

Aos amigos do departamento de anatomia, Amanda Carlos, Alexandre de Melo, Ariane da S. Paulino, Flávio S. Tampelini, Guilherme Cotomacci, Kátia Viegas, Kelly Palombit, Leila M. G. Campos, Luciano Gonçalves, Márcia S. Mizuno, Priscila Girotti, Renata Vasconcelos, Ricardo Teves, Rúbia Misawa, Thaís Souza, Wilma Allemandi, obrigado pela amizade.

À amiga e estaticista Rosana D. Prisco, um agradecimento especial pelo trabalho, pelo carinho e amizade que construímos.

Aos amigos do laboratório de Histologia e Microscopia, Marta Maria da Silva Righetti, Sonia Almeida e Sebastião Aparecido Boleta, por todo o auxílio que me deram na pesquisa, e pela amizade.

Aos colegas do bloco didático de Anatomia, Carlos R. C. Pedro, Devair U. Alves, Edson D. da Silva, Everon L. P. Torres, Giovaldo S. C. José Adão Mendes, Milton P. da Silva, muito obrigado pela prestatividade e aprendizado.

Aos funcionários do Departamento de Anatomia, as secretárias Cristiane V. Pinheiro, Maria Cristina da S. Fustino, Maria Cristina R. Freire, Patrícia R. de 
Campos, do biotério, Fábio, Rodrigo, Renivaldo e Ricardo, aos funcionários da limpeza e porteiros meu agradecimento.

Ao apoio financeiro da CAPES. 
"Sei em quem tenho confiado, e sei também que ele é poderoso para guardar minha confiança até o dia de minha necessidade"

II Timóteo 1, $12 b$ 


\section{RESUMO}

GALVANINI, P. A. Efeitos da Lesão térmica corporal na mucosa e nos componentes do plexo mioentérico do estômago de ratos. 2008. $X X X f$. Dissertação (Mestrado em Ciências Morfofuncionais) - Instituto de Ciências Biomédicas, Universidade de São Paulo, 2008.

O Sistema nervoso entérico está localizados entre as camadas constituintes das paredes do trato gastrintestinal, entre as camadas musculares longitudinal e circular, que se estende por todo o trato digestório, desde o esôfago até o reto. Desordens gastrintestinais são complicações comuns causadas pela lesão térmica. A presente pesquisa avalia, em estômagos de ratos alterações na mucosa e no plexo mioentérico submetidos à Lesão Térmica Corporal. O número de neurônios NADH-d e NADPH-d aumentaram significativamente nos animais queimados. Analisando a média da área do perfil dos neurônios NADH-dr e NADPH-dr evidenciaram uma diminuição significativa de $26 \%$ e $24 \%$, respectivamente, na área do perfil dos neurônios dos animais queimados. Assim, associados o VIP o NO e a acetilcolina se apresentaram de maneira a interferir no esvaziamento gástrico causando alterações na mucosa que foram observadas pela técnica da MEV. Com esses dados, pode-se concluir que a LTC interfere no plexo mioentérico do estômago de ratos causando uma gastroparesia.

Palavras-chave: LTC; Estômago; Plexo mioentérico; Esvaziamento gástrico. 


\section{ABSTRACT}

GALVANINI P. A. Effects of burn injury in mucosal and stomach myentric plexus structure of rats. 2008. $63 \mathrm{f}$. Dissertation (Master in Science Morphofunctional) Institute of Biomedical Sciences, University of São Paulo, 2008.

The enteric nervous system is located among the layer constituents of the gastrintestinal tract. Between the longitudinal and circular muscle layers, which extend throughout the digestory tract from the esophagus to the rectum. Gastrintestinal disorders are common complications caused by burn injury. This research evaluates, in stomach of rats changes in the mucosal and myenteric plexus, subjected burn injury. The number of neurons NADH-d and NADPH-d significantly increased in burned animals. Analyzing the average area of the profile of the neurons $\mathrm{NADH}-\mathrm{dr}$ and NADPH-dr, showed a significant decrease of $26 \%$ and $24 \%$, respectively, in the area of the profile of the neurons of the burned animals. Thus, the association of VIP, NO and acetylcholine is presented so as to interfere with gastric

emptying causing changes in the mucosal wich were observed by the technique of MEV. With this data, it can be conclude that the burn injury interferes in the myenteric plexus of the stomach of rats causing a gastroparesis.

Key-words: burn injury, stomach myenteric plexus, gastric emptiyng 


\section{LISTA DE ABREVEATURAS}

SNC - Sistema Nervoso Central

SNE - Sistema Nervos Entérico

GI - Trato gastrintestinal

c10 - grupo controle de 10 dias

q10 - grupo queimado de 10 dias

LTC - Lesão Térmica Corporal

NADH-d - NADH-diaphorase

NADPH-d - NADPH-diaphorase

NADH-dr - Neurônios NADH diaphorase reativos

NADPH-dr - Neurônios NADPH-diaphorase reativos

NBT - Nitro Blue Tetrazolium

VIP - Peptídeo Intestinal Voasoativo

SP - Substância P

NO - Óxido nítrico

AChE - Acetilcolinesterase

AChE-r - Neurônios acetilcolinergicos reativos

HE - hematoxilina-eosina

MEV - Microscopia Eletrônica de Varredura 


\section{LISTA DE FIGURAS}

Figura 1. A- região ventral onde, após a tricotomia, foi exposta a pele de uma área de aproximadamente $24 \mathrm{~cm}^{2}$. B- dispositivo idealizado para realização da LTC com área de $21 \mathrm{~cm}^{2}$ (cerca de15\% da superfície corpórea). C- pele da região dorsal de animal do grupo q10 (10 dias pós LTC). .26

Figura 2. Demonstra dados referentes ao peso (g) coletados diariamente dos animais dos grupos c10 e q10 no decorrer dos 10 dias após a LTC.

Figura 3. Demonstra a área dos neurônios do estômago de animais dos grupos c10

e q10 evidenciados pela técnica do NADH-d.

Figura 4. Demonstra a área dos neurônios do estômago de animais dos grupos c10 e q10 evidenciados pela técnica do NADPH-d.

Figura 5. Demonstra a espessura $(\mu \mathrm{m})$ da mucosa gástrica dos animais dos grupos c10 e q10.

Figura 6. Fotomicrografias de preparados de membrana do estômago de rato dos grupos c10 (A, C, E) e q 10 (B, D, F) evidenciando gânglios com neurônios mioentéricos NADH-d positivos. Setas indicam diferença de intensidade apresentada pelos grupos estudados. Estrela indica no gânglio o número maior de neurônios grandes no grupo c10 e neurônios menores no grupo q10. 48

Figura 7. Fotomicrografias de preparados de membrana do estômago de rato dos grupos c10 (A, C, E) e q 10 (B, D, F) evidenciando gânglios com neurônios mioentéricos NADPH-d positivos. Setas indicam contorno regular citoplasmático nos neurônios do grupo c10 e contorno irregular no grupo q10. Estrelas indicam gânglio com maior número de neurônios marcados no grupo q10. 39

Figura 8. Fotomicrografias de preparados de membrana do estômago de rato dos grupos c10 (A, C, E) e q 10 (B, D, F) evidenciando gânglios com neurônios mioentéricos AChE-r. Setas indicam contorno regular citoplasmático nos neurônios do grupo c10 e contorno irregular no grupo q10. Estrela indica no grupo q10, apenas neurônios pequenos apresentando reatividade ao marcador neuronal. 40

Figura 9. Demonstra gânglio com neurônios imunorreativos ao VIP. A- grupo c10, B- grupo q10; Setas indicam varicosidades maiores e mais fortemente reativas em

A do que em B. 41

Figura 10. Demonstra gânglio com neurônios imunorreativos a SP. A- grupo c10, Bgrupo q10; Setas indicam varicosidades gânglio com imunoreatividade em $A$, enquanto que em $B$ a imunoreatividade é muito baixa. 
Figura 11 Fotomicrografia da mucosa gástrica evidenciada pela técnica de Microscopia Eletrônica de Varredura, (A; C; E) evidenciam mucosa gástrica de animais pertencentes ao grupo c10 e (B; D; F) evidenciação da mucosa de animais do grupo q10. .43

Figura 12 Demonstra o gânglio mioentérico evidenciado pela técnica histológica de picro-sirius e sobre luz polarizada. As setas indicam o gânglio com contorno de fibras colágenas. A - c10 e B - q10. No grupo q10 houve aumento de fibras colágenas ao redor do gânglio. 44

Figura 13 Demonstra a mucosa gástrica evidenciada pela técnica histológica de picro-sirius sobre luz polarizada A - grupo c10 e B - grupo q10. As setas indicam fibras colágenas de maior espessura em $\mathrm{B}$ 45

Figura 14 Demonstra o gânglio mioentérico evidenciado pela técnica histológica de verhoeff. As setas indicam o gânglio com pequena quantidade de fibras elásticas A - grupo c10 e B - grupo q10. No grupo q10 houve aumento de fibras elásticas no gânglio 46

Figura 15 Demonstra o gânglio mioentérico evidenciado pela técnica histológica de hematoxilina-eosina (HE). As setas indicam a espessura da mucosa gástrica. A - grupo c10 e B - grupo q10. No grupo q10 houve aumento da espessura da mucosa. 


\section{SUMÁRIO}

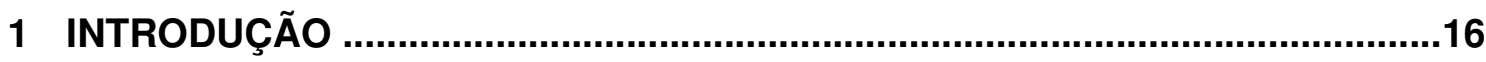

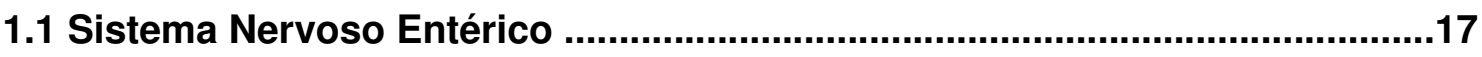

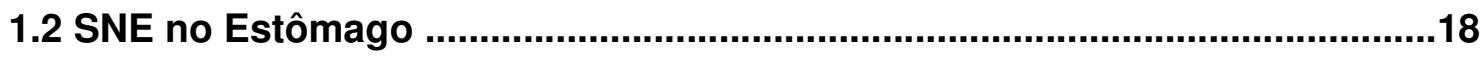

1.3 Lesão Térmica Corporal (LTC) …...............................................................19

1.4 LTC e sua Influência no Sistema Digestório ..................................................20

2 OBJETIVOS

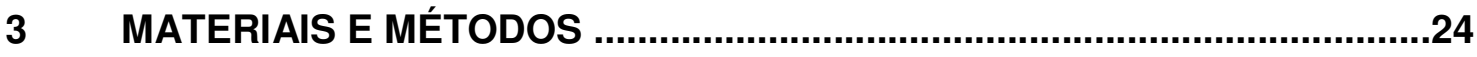

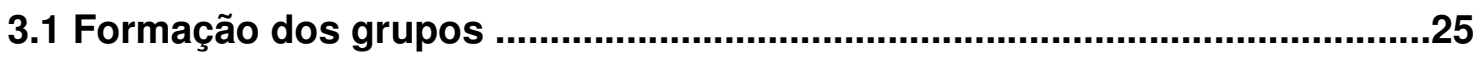

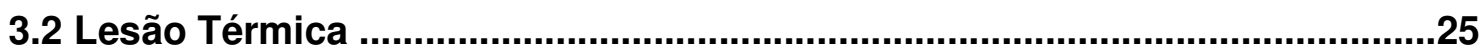

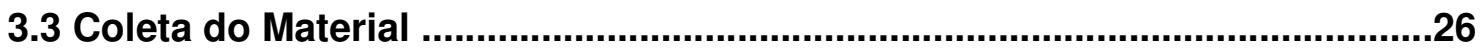

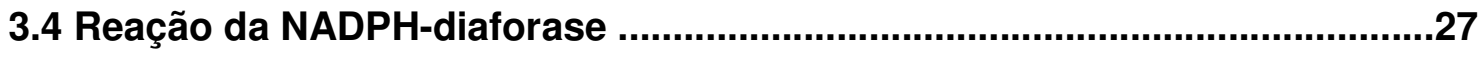

3.5 Reação da NADH-diaforase ............................................................................27

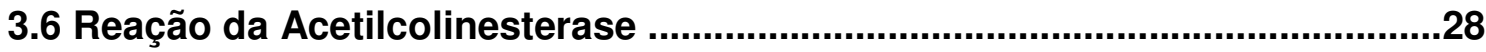

3.7 Reação Imunohistoquímica para o Peptídeo Intestinal Vasoativo (VIP) e a

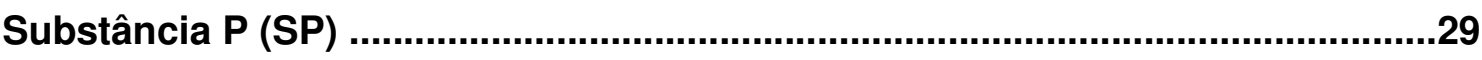

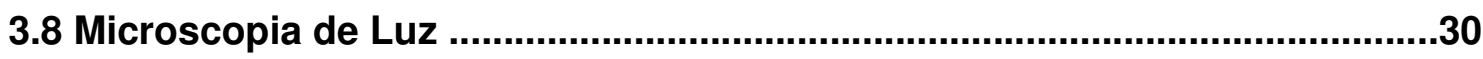

3.9 Microscopia Eletrônica de Varredura (MEV) ...................................................30

3.10 Análise Quantitativa e Morfométrica …….........................................................

3.11 Tratamento Estatístico ..........................................................................31

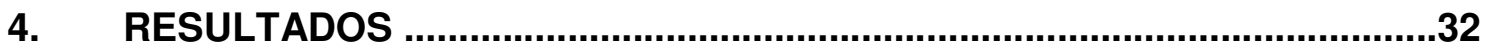

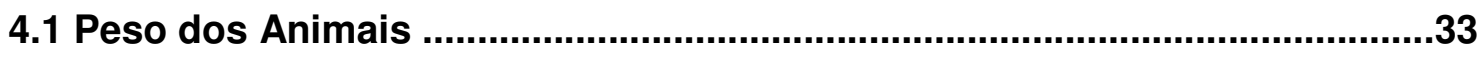

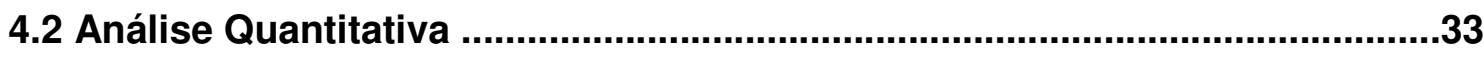

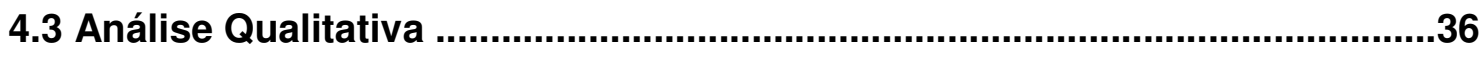




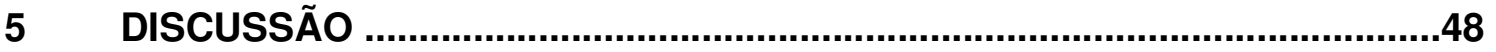

6 CONCLUSÕES

REFERÊNCIAS 
1 INTRODUÇÃO 


\subsection{Sistema Nervoso Entérico (SNE)}

A classificação do sistema nervoso autônomo feita com bases anatômicas e funcionais nas seguintes subunidades: simpático, parassimpático e entérico (SNE) foi previamente estabelecida por Langley (1921). Relativamente à sua organização, os neurônios do SNE apresentam-se em quantidade variável em gânglios geralmente achatados, formados por duas camadas dessas células, o que os diferencia dos gânglios autônomos simpático e parassimpático. Uma outra característica refere-se às projeções das fibras nervosas provenientes da parte central do sistema nervoso (SNC), que ligam-se ao gânglio entérico são maiores, quando comparadas às que se ligam ao outro gânglio periférico (FURNESS e COSTA, 1987).

Localizados entre as camadas constituintes das paredes do trato gastrintestinal (Gl), os plexos do SNE constituem o plexo mioentérico, entre as camadas musculares longitudinal e circular, e que se estende por todo o tracto digestório, desde o esôfago até o reto (AUERBACH, 1864; STOHR, 1930; SCHABADASH, 1930a, 1930b; LI, 1940). Um segundo plexo, o plexo submucoso, está abaixo da camada mucosa e acima da musculatura circular e é encontrado nos intestinos delgado e grosso, podendo ser subdividido nas seguintes partes: o plexo submucoso interno (plexo de Meissner) que se encontra abaixo da mucosa; o plexo submucoso externo (plexo de Schabadash ou de Henle) e o plexo intermediário, próximo à camada circular e disposto entre os plexos submucoso interno e externo (HENLE, 1871).

Através de métodos farmacológicos, neuroquímicos e morfológicos para se identificar os diferentes componentes neuronais, foi possível classificar as funções distintas dos neurônios dos plexos mioentérico e submucoso. Desta forma, foram identificados dezessete tipos de neurônios intrínsecos, catorze destes, no intestino delgado de cobaias (FURNESS, 2000).

Sob o aspecto funcional, Furness (2000) encontrou no plexo mioentérico do intestino delgado cinco tipos de neurônios: neurônios excitatórios e inibitórios da musculatura intestinal; neurônios secretomotor/vasodilatador; neurônios secretomotores que não são vasodilatadores e neurônios de inervação de células entero-endócrinas, sendo que a inervação motora de células secretomotoras de ácido do estômago foram consideradas como um tipo especial de neurônio 
secretomotor. Neurônios aferentes primários (IPANs) com o corpo celular na parede do tracto digestório, também foram detectados por Furness (2006), que os subdividiu em dois tipos: IPANS e os neurônios intestinofugal, responsáveis por conduzir as informações para os gânglios simpáticos.

Em estudos eletrofisiológicos, os IPANS são classificados como neurônios sensoriais intrínsecos, pertencentes ao tipo morfológico Dogiel tipo II, o qual possui um grande corpo celular com superfície lisa e um ou dois prolongamentos longos (BERTRAND e BORNSTEIN, 2002; SAYEGH e RITTER, 2003).

No plexo submucoso, o neurônio secretomotor e o neurônio vasomotor controlam diretamente o circuito reflexo local sendo que esses dois tipos de neurônios secretomotores intestinais são respectivamente, colinérgicos e não colinérgicos (FURNESS, 2000).

\subsection{SNE no estômago}

Em se tratando de estômago de ratos, os gânglios do plexo mioentérico, na região aglandular, encontram-se localizados entre as camadas longitudinal e circular da túnica muscular; já na região glandular, além de estarem contidos entre os estratos longitudinal e circular, são também evidenciados no interior da camada longitudinal da túnica muscular (OLIVEIRA et al., 2000). A organização, o arranjo, bem como o número de neurônios presentes no plexo é diferente quando se compara as regiões aglandular (OLIVEIRA et al., 2000) e glandular (FREGONESI et al., 1998; OLIVEIRA et al., 2000). Assim, na região aglandular há uma maior concentração de neurônios próximos à região central da prega limitante do que na região adjacente à curvatura maior (MOLINARI et al., 2002) ao passo que na região aglandular, a densidade neuronal é maior próximo à curvatura maior (FREGONESI et al., 1998; OLIVEIRA et al., 2000).

O óxido nítrico é observado como principal transmissor inibitório, o qual juntamente com o VIP é responsável pelo relaxamento do músculo liso (HOLZERPETSCHE et al., 1989; LEFEBVRE et al., 1992; CURRO e PREZIOSI, 1998). Quase todos os neurônios dos gânglios entéricos do estômago de cobaias são excitados por transmissão nicotínica e sua rápida resposta despolarizante para estimulação vagal é bloqueada por hexometonium (BERTHROUD, 1996). Para esse autor, a maior parte dos neurônios do plexo mioentérico do estômago de ratos, em particular, 
um grupo de fibras contendo o VIP é projetada na camada circular e na muscular da mucosa, ocorrendo entrada de receptor excitatório para terminais nervosos préganglionares vagal.

\subsection{Lesão Térmica Corporal (LTC)}

As queimaduras representam um importante problema de saúde pública, visto que demandam uma série de cuidados para tentar minimizar os efeitos da lesão, não somente na pele onde é visível o trauma, mas também em todo o organismo, pois a queimadura se caracteriza por apresentar destruição de tecidos, o que induz a uma ativação de processos catabólicos, na intenção de reparar a área afetada. Com isso, o metabolismo orgânico se intensifica, aumentando a energia consumida e diminuindo o substrato energético de reservas protéicas e de gordura (De SOUZA et al., 1998)

No Brasil, Rossi et al. (1998), descreveram que a queimadura ocorre com maior freqüência em pacientes com até doze anos de idade e que $50 \%$ são menores de três anos de idade. Uma análise retrospectiva de pacientes queimados dos Hospital Universitário de Ribeirão Preto, no Estado de São Paulo,no período de 1990 e 1995, De Souza et al. (1998) descrevem que 78,6\% dos acidentes por queimaduras eram determinados por causas ocupacionais ou domésticas e destes $71,2 \%$ se queimaram diretamente com o fogo. A taxa de mortalidade era diretamente proporcional ao tamanho da área afetada.

Nos Estados Unidos, são estimadas que um milhão de pessoas sofrem queimaduras por ano, destas setecentas mil procuram o departamento de emergências e quarenta e cinco mil ficam hospitalizadas. Deste total de hospitalizados, 5 a $6 \%$ morrem devido a infecções oriundas das queimaduras. Além dos ferimentos na pele, os quais são visíveis, a lesão apresenta múltiplas conseqüências em todo o organismo. O Gl é acometido em seu padrão de comportamento normal, afetando nas respostas imunes. (GOSAIN e GAMELLI, 2005). 


\subsection{LTC e sua influência no Sistema Digestório}

Pacientes hospitalizados devido a queimaduras freqüentemente morrem de patologias oportunistas originadas no intestino (SORI et al., 1988; DEITCH et al., 1996). Essa idéia está associada ao deslocamento de endotoxinas e de proteinases bacterianas da luz intestinal em direção à circulação portal, onde pode exercer efeitos na função hepatocelular e sistema imune. Essa opinião foi suposta há aproximadamente 50 anos por Scweinburg et al. (1950) e por Fine et al. (1959).

Durante esse período houve o entendimento de que o Gl impedia 0 desenvolvimento de defesas imunes contra a septicemia oriunda da lesão térmica. Iniciando com o conceito de que do intestino procediam bactérias que causavam danos a órgãos distantes, investigadores têm delineado uma complexa série de mudanças físicas para atuarem como barreira no GI (GOSAIN e GAMELLI, 2005). Até o momento sabe-se que a linfa mesentérica é um dos caminhos pelos quais as endotoxinas e bactérias ocupam outros espaços e que desviar essa linfa para um local de excreção é de fundamental importância para diminuir infecções originadas pelo intestino (GOSAIN e GAMELLI, 2005).

Desordens gastrintestinais são complicações comuns causadas pela lesão térmica. Úlceras gástricas e duodenais são exemplos dessas complicações. Essas úlceras, chamadas de úlcera de Curling, foram primeiramente descritas por Curling (1842), que procurou minimizar os efeitos desta injuria com anti-ácidos e suplementação nutricional. No entanto, a distensão gástrica e o desconforto gastrintestinal mantiveram-se mesmo com a administração de medidas profiláticas (CURRERI et al., 1986; WILMORE et al., 1988).

As respostas do GI superior e do SNC quanto aos efeitos e a capacidade de realizarem suas funções após a lesão térmica foi estudada por Keity (1980), o qual observou que o estresse induziu a uma alteração na contratilidade do estômago dificultando o seu esvaziamento, dados esses que concordam com os estudos de Koo et al., 1985.

Segundo Alican et al., 2005, o esvaziamento de líquidos e sólidos do estômago depende da função da musculatura gástrica e do esfíncter pilórico. Após a lesão térmica, tanto a musculatura quanto a função do esfíncter foram afetadas, assim como o ambiente no interior do estômago, com conseqüências no duodeno que ficaram demasiadamente ácidos, resultando em úlceras. 
Para Ramzy et al. (2000) a queimadura cutânea severa causa uma temporária vasoconstrição mesentérica, alterando a integridade da mucosa intestinal; conseqüentemente, há morte de células epiteliais do intestino por apoptose. Além disso, os autores demonstraram que há uma forte correlação entre o fluxo sanguíneo da artéria mesentérica e a distribuição do sangue em todo o tecido intestinal, principalmente em estados de oclusão vascular, porém, esta hipoperfusão momentânea causada pela lesão térmica cutânea é insuficiente para aumentar significativamente a apoptose epitelial. Esses dados permitiram concluir que quando há um sinal do aumento de apoptose epitelial no intestino, este associam-se primeiramente a mediadores pró-inflamatórios induzidos pela queimadura.

A lesão térmica induz a atrofia intestinal e causa alterações marcantes na morfologia, função e crescimento celular no epitélio do intestino delgado (CARTER el al. 1986; DEITCH, 1990; CARTER et al., 1992; EZZELL et al., 1993). Após a lesão térmica, a atrofia da mucosa intestinal foi previamente descrita baseada no decréscimo do peso da mucosa, redução da proliferação das células intestinais, que foram demonstradas pela diminuição do DNA e da síntese de proteína (CARTER et al., 1986).

Nos estudos de Varedi et al. (2000), demonstrou-se que a lesão térmica reduz a atividade mitótica nas criptas intestinais em ratos. A avaliação da atividade mitótica, bem como da região proliferativa das criptas, no intestino delgado de ratos controle e queimados, revelaram diferenças espaciais. Foi verificado que a lesão inibiu a mitose em células proliferativas situadas nas criptas intestinas. A maioria das zonas de proliferação nas criptas intestinais dos animais queimados mostraram redução mitótica 6 horas após a lesão, quando comparados com o grupo controle. Feita a contagem de células apoptóticas, observou-se nos ratos controle um baixo nível de atividade apoptótica, mas que em animais submetidos à lesão térmica, a apoptose era significativa em algumas zonas de proliferação. 

OBJETIVOS 
Com a utilização de técnicas de microscopias de luz e eletrônica de transmissão pretende-se avaliar na presente pesquisa, em estômagos de ratos jovens submetidos à LTC:

1. A disposição e o arranjo dos gânglios do plexo mioentérico;

2. Os tipos de neurônios constituintes do plexo, relativamente às marcações histoquímicas para a AChE e NADPH, bem como para as marcações imunohistoquímicas para a SP e VIP;

3. O número total de neurônios estimado para o estômago, evidenciados pelas técnicas histoquímicas da NADH e NADPH;

4. A área do perfil celular dos neurônios reativos à NADH e NADPH;

5. A ultraestrutura dos neurônios constituintes do plexo mioentérico;

6. A ultra-estrutura e a espessura da mucosa do estômago. 


\subsection{Formação dos grupos}

Foram utilizados ratos machos da linhagem Wistar (Rattus norvegicus) adultos (90 dias), provenientes do Biotério Central do Instituto de Ciências Biomédicas da Universidade de São Paulo separados nos seguintes grupos: q10 (queimados com 10 dias após LTC) e c10 (controle com 10 dias após tricotomia).

\subsection{Lesão térmica}

Para serem submetidos à lesão térmica corporal, os animais do grupo q10 foram anestesiados com injeção intraperitoneal de pentobarbital sódico (60$70 \mathrm{mg} / \mathrm{kg}$ ) que também foi realizada nos animais dos grupos c10 a fim de se evitar, segundo Ibebunjo e Martyn (2001), possíveis influências do anestésico nos resultados.

Posterior à anestesia, procedeu-se à tricotomia de uma área de aproximadamente $24 \mathrm{~cm}^{2}$ (cerca de $30 \%$ da superfície corpórea) das regiões do dorso e do abdome dos animais de todos os grupos, a fim de se expor a pele. Em seguida, a pele exposta das regiões dorsal e ventral dos animais do grupo q10 foi colocada em contato com água a $85^{\circ} \mathrm{C}$, através de um dispositivo com uma área de exposição com $21 \mathrm{~cm}^{2}$. Tanto a área a ser lesada como o tempo de escaldamento (10 segundos para a região dorsal e 5 segundos para a região ventral) foram estabelecidos de acordo com o protocolo preconizado por Walker e Mason (1968).

Após a LTC, os animais foram mantidos, sem restrições de ração e de água, em gaiolas individuais, as quais permitem a higienização diária e o não contato dos animais com as suas fezes, a fim de eliminar possíveis contaminações. 


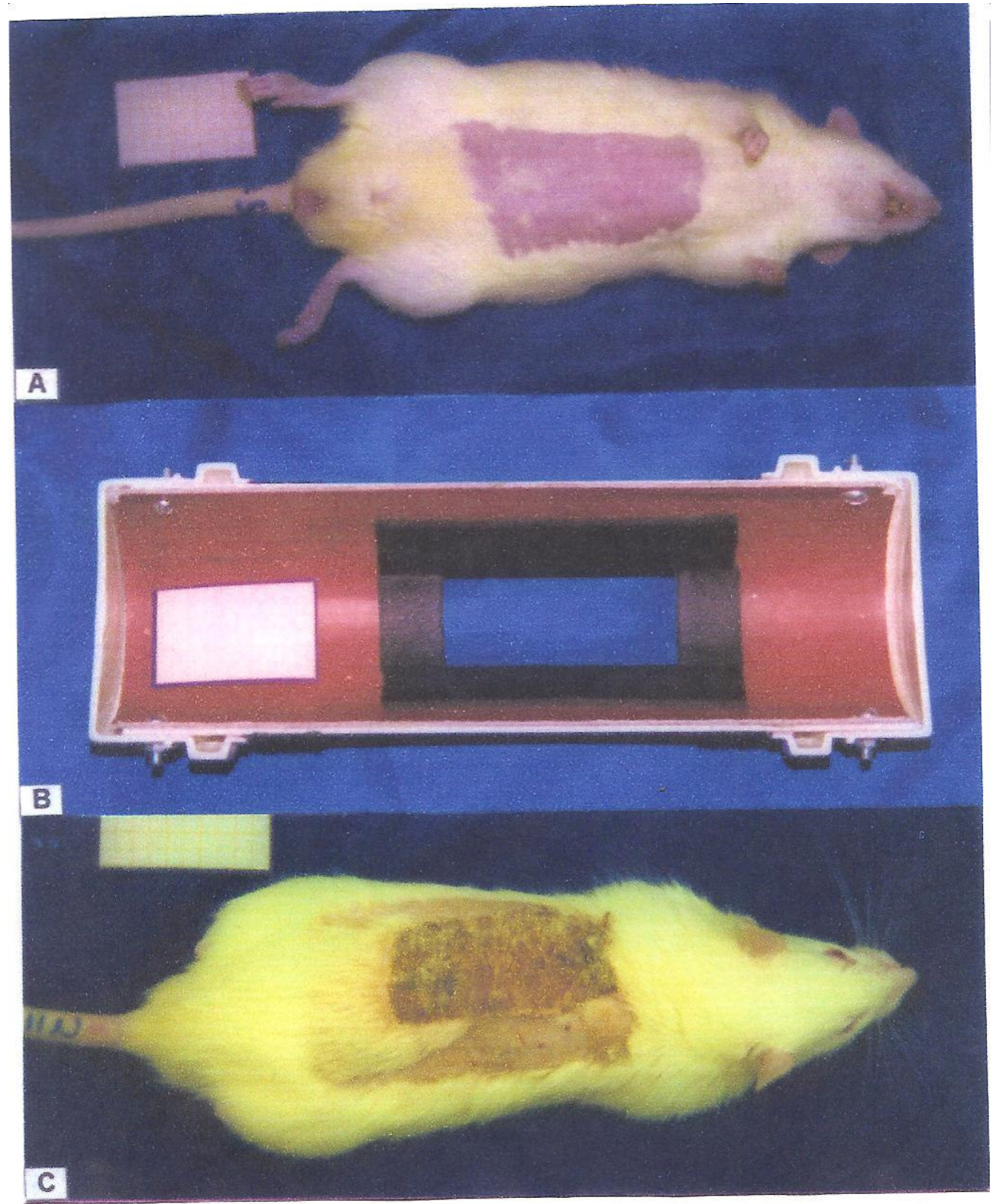

Figura 1. A- região ventral onde, após a tricotomia, foi exposta a pele de uma área de aproximadamente $24 \mathrm{~cm}^{2}$. B- dispositivo idealizado para realização da LTC com área de $21 \mathrm{~cm}^{2}$ (cerca de15\% da superfície corpórea). C- pele da região dorsal de animal do grupo q10 (10 dias pós LTC).

\subsection{Coleta do material}

Após o sacrifício dos animais de todos os grupos com dose excessiva de anestésico seguiu-se à imediata laparotomia, quando se retirou o estômago. 
No decorrer dos períodos pós LTC, peso corpóreo dos animais de todos os grupos foi medido diariamente.

\subsection{Reação da NADPH-diaforase}

A fim de se evidenciar os neurônios nitrérgicos, foi obtido o estômago de 10 animais, sendo 5 do grupo c10 e 5 do grupo q10 que, após lavados tiveram suas extremidades ligadas e preenchidos com tampão fosfato $0,1 \mathrm{M}(\mathrm{pH} \mathrm{7,4)}$. Em seguida, os segmentos foram imersos, por um período de 30 minutos. Findo o período de fixação, os espécimes foram submetidos, durante 10 minutos, a 3 lavagens em tampão fosfato e imersos por 90 minutos no seguinte meio de incubação ${ }^{1}$ em tampão fostato $0,1 \mathrm{M}(\mathrm{pH} 7,4): 50 \mathrm{mg}$ de NBT; $100 \mathrm{mg}$ de $\beta$-NADPH; $0,3 \%$ de Triton $\mathrm{X}-100$. Após a reação, os segmentos foram abertos e lavados 3 vezes em tampão fosfato por 5 minutos e então imersos em solução de paraformoldeído a $4 \%$ em tampão fosfato.

Para a confecção dos preparados totais de membrana, os estômagos foram abertos e distendidos a fim de serem submetidos à microdissecção sob microscópio estereoscópico com transiluminação ${ }^{2}$, quando se removeu as camadas mucosa e submucosa, com auxílio de pinças e tesouras oftalmológicas. Em seguida, os preparados totais de membrana foram montados com glicerina tamponada entre lâmina e lamínula e foram fotografados em fotomicroscópio. binocular ${ }^{3}$.

\subsection{Reação da NADH-diaforase}

Os 5 estômagos do grupo controle e os outros 5 do grupo queimado foram lavados e distendidos em solução de $\mathrm{Krebs} \mathrm{pH}$ 7,3 contendo: 1,3 $\mathrm{g}$ de $\mathrm{NaHCO}_{3}, 0,24$ $\mathrm{g}$ de $\mathrm{MgCl}_{2}, 6 \mathrm{H}_{2} \mathrm{O}, 0,44 \mathrm{~g}$ de $\mathrm{KCl}, 0,165 \mathrm{~g}$ de $\mathrm{NaH}_{2} \mathrm{PO}_{2}, 7,05 \mathrm{~g}$ de $\mathrm{NaCl}$ e 0,27 $\mathrm{g}$ de $\mathrm{CaCl}_{2}$ em 1 litro de água destilada e, imediatamente, submetidos aos procedimentos para evidenciação neuronal. Estes constam de duas lavagens de 10 minutos em

solução de Krebs pH 7,3; permeabilização em Krebs contendo Triton X-100 ${ }^{\circledR(\text { Sigma) }}$ a 0,3\% por cinco minutos; mais duas lavagens de 10 minutos em Krebs; e incubação

\footnotetext{
${ }^{1}$ Sigma.

23 Zeiss.
} 
por 45 minutos em meio de reação consistindo de: $25 \mathrm{ml}$ de solução estoque de $\mathrm{NBT}^{\text {(Sigma) }}$ (NBT, solução estoque na concentração de $0,5 \mathrm{mg} / \mathrm{ml}$ ), $25 \mathrm{ml}$ de tampão fosfato de sódio $0,1 \mathrm{M}, 50 \mathrm{ml}$ de água destilada e 0,05 g de $\beta$-NADH ${ }^{(\text {Sigma })}$ ). Em seguida, foram fixados em formol a $10 \%$ em tampão fosfato $0,1 \mathrm{M} \mathrm{pH} \mathrm{7,3}$ para interromper a reação e, submetidos à elaboração de preparados de membrana e montados entre lâmina e lamínula.

Para a realização dos preparados de membranas, o estômago foi secionado, separando-se as faces ventral e dorsal. Nestes, as camadas mucosa e submucosa foram removidas com auxílio de instrumental cirúrgico sob microscópio estereoscópio com transiluminação; a seguir, os preparados totais de membrana foram montados com glicerina tamponada entre lâmina e lamínula e foram fotografados em fotomicroscópio binocular ${ }^{3}$.

\subsection{Reação da Acetilcolinesterase (AChE)}

Seis animais foram utilizados para a realização desta técnica, sendo 3 c10 e 3 q10. Após a laparotomia os estômagos foram retirados e lavados com solução salina e posteriormente preenchidos com paraformoldeído a 4\% em tampão fosfato, sendo suas extremidades fechadas com cordonê, formando uma "bexiga". Os estômagos permaneceram preenchidos e imersos neste fixador por um período de 4 horas a temperatura ambiente, sendo em seguida lavados durante 24 horas em solução de Krebs contendo hialuronidase ${ }^{(2000}$ UTR Apsen) e tetraisopropil pirofosforamida (iso-OMPA) ${ }^{(\text {Sigma) }}$. A incubação foi realizada por um período de 48 horas a $4 \stackrel{\circ}{\mathrm{C}}$, em meio contendo $0,17 \mathrm{M}$ de acetilcolina(Sigma) $6,5 \mathrm{ml}$ de tampão fosfato $(0,1 \mathrm{M}, \mathrm{pH} 7,1), 0,5 \mathrm{ml}$ de citrato de sódio $(100 \mathrm{mM}), 1 \mathrm{ml}$ de sulfato de cobre $(30 \mathrm{mM}), 1 \mathrm{ml}$ de água destilada e $1 \mathrm{ml}$ de ferricianeto de potássio $(5 \mathrm{mM})$, acrescentando-se tetraisopropil pirofosforamida e hialuronidase.

Após o período de incubação, os preparados de membrana foram dissecados, removendo-se as camadas mucosa e submucosa, como foi descrito nos itens anteriores. Os preparados de membrana foram então desidratados em álcool $80 \%, 90 \%$ e $3 \times 100 \%$ durante dois minutos, diafanizados em xilol por dois minutos 
em três passagens e montados entre lâmina e lamínula com resina sintética(Fisher Chemical).

\subsection{Reação Imunohistoquímica para o Peptídeo Intestinal Vasoativo (VIP) e a Substância P (SP)}

Após a eutanásia dos animais, retirou-se os estômagos de seis ratos, sendo 3 de cada grupo experimental, foram lavados com PBS 0,1M pH 7,3 e preenchidos com fixador Zamboni, sendo suas extremidades fechadas com cordonê, formando uma "bexiga". Os estômagos foram armazenados no mesmo fixador por um período de 24 horas a $4^{\circ} \mathrm{C}$. Após o período de fixação, foram feitos sucessivas lavagens em álcool $80 \%$ para remoção do ácido pícrico. O material foi desidratado em álcool 95\% por 30 minutos e álcool 100\% pelo mesmo período, diafanizados em Xilol por 30 minutos e reidratados em seqüencia decrescente de alcoóis 100\%, 80\% e 50\% permanecendo 30 minutos em cada. Armazenou-se em PBS 0,1M pH7,3 com Azida sódica a 0,4\% em geladeira para posterior dissecção.

Para a imunomarcação neuronal do plexo mioentérico, separou-se a camada mucosa das camadas circular e longitudinal e, posterior retirada da camada circular, permanecendo a musculatura longitudinal com o plexo mioentérico. Os seguimentos foram lavados com PBS 0,1M pH7,3 com Triton X-100 a 0,3\% 2 X 10 minutos sob agitação. Incubou-se em $100 \mu \mathrm{l}$ de soro de cabra a $10 \%$ sob agitação em temperatura ambiente por 2 horas. Foram então, incubados em 100 $\mu$ de anticorpo primário anti VIP ou anti Substância P sob agitação a temperatura ambiente por 22 horas e 2 horas em estufa a $37^{\circ} \mathrm{C}$. Após este período o material foi lavado $3 \times 5$ minutos com PBS $0,1 \mathrm{M}$ pH 7,3 sob agitação e incubados em $100 \mu l$ de anticorpo secundário (Ac IgG anti-rabbit - FITC) sob agitação por 2 horas. $O$ anticorpo secundário não reage à presença de luz, então os microtubos foram envoltos por papel alumínio. Lavou-se em PBS $0,1 \mathrm{M}$ pH 7,3 3 X 5 minutos sob agitação e montadas as membranas entre lâmina e lamínula com glicerol tamponado (9:1). 


\subsection{Microscopia de luz}

Os estômagos de 6 ratos, sendo 3 do grupo c10 e 3 do grupo q10, foram acondicionados para fixação em tubos apropriados com solução de bouin em quantidade 2 vezes o seu tamanho por 24 horas. Após esta etapa os estômagos sujeitos a técnica de microscopia de luz seguiram à desidratação em série crescente de álcoois (70 ao absoluto), diafanização em xilol e em seguida, inclusão em parafina. $O$ processamento histológico foi inteiramente realizado no Laboratório Multiusuário de Histologia do Departamento de Anatomia do Instituto de Ciências Biomédicas da Universidade de São Paulo. Cortes semi-seriados de $5 \mu \mathrm{m}$ de espessura realizados naregião aglandular do estômago numa área de secção transversa do órgão,foram submetidos às técnicas de coloração da Hematoxilinaeosina (BEHMER; TOLOSA; FREITAS-NETO, 1975) que é clássica básica, dicrômica e geral, uma vez que possui dois corantes: hematoxilina, que cora todos os núcleos de todas as células e eosina que cora o citoplasma de todas as células. Verhoeff (VERHOEFF F. H., 1908), técnica que cora fibras elásticas, que foram analisadas no gânglio mioentérico.Picro-sirius (MONTES; JUNQUEIRA, 1991) para a diferenciação dos tipos de fibras colágenas sob luz polarizada (Carl Zeiss Microimaging, modelo Axioshop 40, Göttingen, Alemanha). A montagem dos cortes foi realizada entre lâmina e lamínula, com Entellan (MERCK, Darmstadt, Alemanha).

\subsection{Microscopia Eletrônica de Varredura (MEV)}

Três estômagos de animais oriundos de cada grupo experimental (c10 e q10), foram utilizados para o estudo da morfologia ultra-estrutural. Ao completarem 10 dias após a tricotomia e LTC no grupo q10, os animais foram anestesiados com solução anestésica (combinado de cloridrato de tiletamina e cloridrato de zolazepam, na proporção de 0,8ml/kg de peso corpóreo, i.m., dose anestésica -Zoletil(R), e perfundidos através do ventrículo esquerdo com solução de Karnovsky. Os espécimes seguiram imersos na mesma solução fixadora por um período de 24 horas . Quando, então, foram lavados em solução fisiológica e então pós-fixados por imersão em uma solução aquosa de tetróxido de ósmio a 1\%, por 2 horas, seguido de desidratação em série crescente de alcoóis (de $70^{\circ}$ ao absoluto), onde permaneceram no álcool absoluto até serem submetidos ao ponto crítico (BAL-TEC, 
modelo CPD-030, Schalksmühle, Alemanha). Feita esta etapa, os fragmentos foram devidamente posicionados para observação em bases metálicas apropriadas, metalizados com ouro (BALZERS, modelo SCD-040 Reinraumtechnik Lanz, Alemanha) e analisados em um microscópio eletrônico de varredura (LEO, modelo 435 VP, Departamento de Anatomia dos Animais Domésticos e Silvestres da Faculdade de Medicina Veterinária e Zootecnia).

\subsection{Análise quantitativa e morfométrica}

A análise quantitativa dos neurônios foi efetuada com auxílio de microscópio óptico, com objetiva de 16x. Foram quantificados 80 campos microscópicos aleatórios, pela superfície dos preparados totais de membrana. Todos os neurônios de cada campo foram contados. Para a análise do tamanho da área do corpo celular foram mensurados 50 neurônios de cada estômago de todos os animais, utilizandose para tanto, um software analisador de imagens ${ }^{4}$

\subsection{Tratamento estatístico}

Os dados referentes ao número de neurônios, espessura da mucosa e a morfometria, foram submetidos ao Teste estatístico t-student e Teste de Kolmogorov-Smirnov, respectivamente.

\footnotetext{
${ }^{4}$ image pro-plus 3.4 .5
} 


\subsection{Peso dos Animais}

Os dados dos pesos de cada animal foram realizados diariamente, e observou-se que no grupo controle depois de realizado a anestesia e tricotomia apresentaram pequena redução de peso corporal e imediata recuperação do mesmo, tanto que ao final dos 10 dias os animais tinham peso superior ao peso inicial. Já no grupo queimado, a redução do peso corporal foi muito mais acentuada, com maior perda observada entre o quarto e o sexto dias. Após este período houve recuperação, porém não foi o bastante para restabelecer o peso inicial (Figura 2).

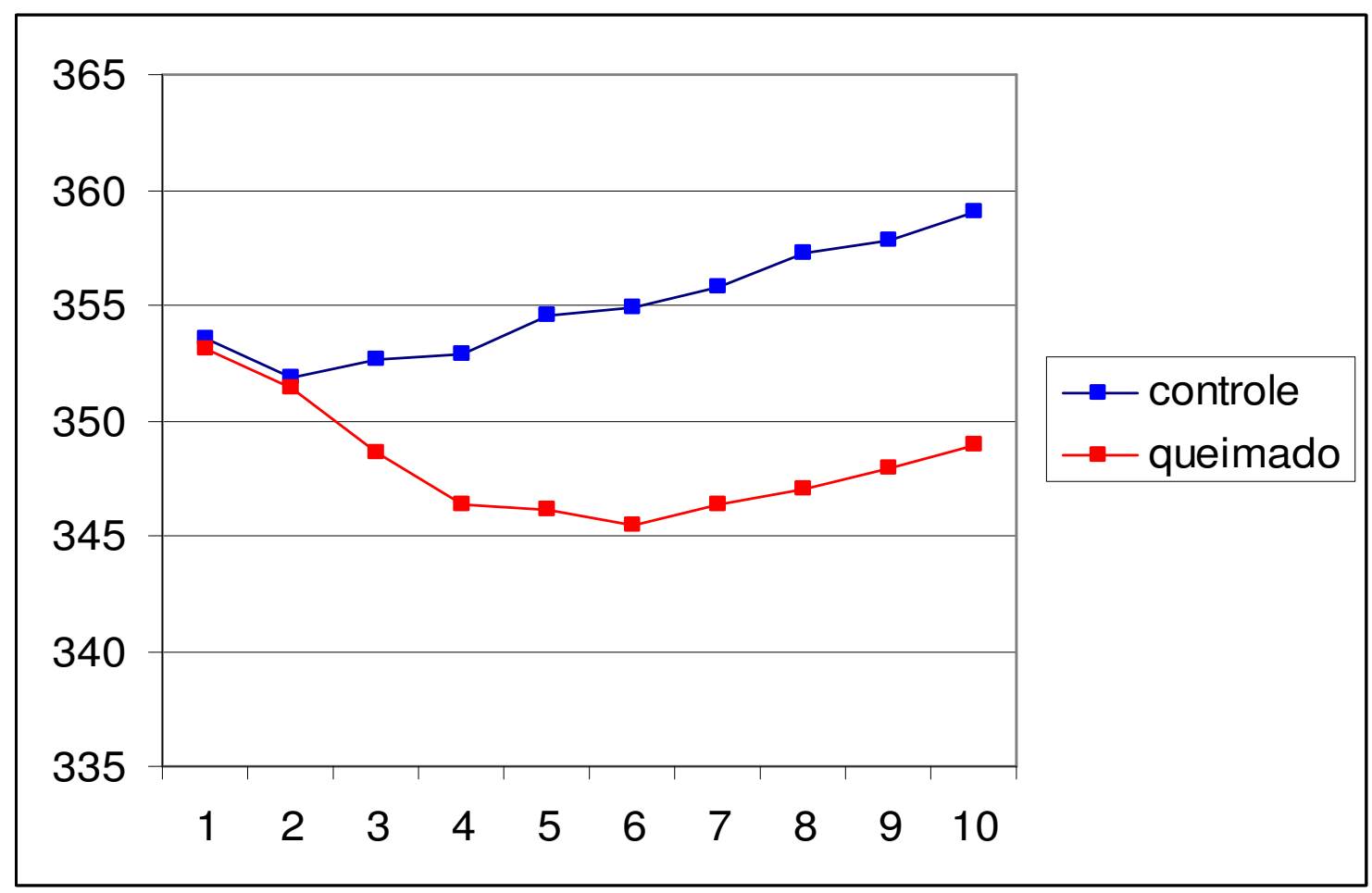

Figura 2. Demonstra dados referentes ao peso (g) coletados diariamente dos animais dos grupos c10 e q10 no decorrer dos 10 dias após a LTC.

\subsection{Análise quantitativa}

Até o presente, os preparados totais de membrana do estômago submetidos às técnicas da e NADH-d e NADPH-d foram avaliados quantitativamente.

Assim, para a técnica da NADH-d onde foram contados os neurônios em 80 campos do estômago, verificou-se uma média ( \pm desvio padrão) do número 
total estimado de $3455,0 \pm 237$ para os animais do grupo $\mathrm{c} 10$ e de $4305,8 \pm 201,3$ para os animais do grupo q10, o que correspondeu a um aumento significativo aproximado de $25 \%$ no número de neurônios nos animais queimados $(p<0,001)$.

Relativamente à técnica da NADPH-d verificou-se respectivamente para os animais dos grupos c10 e q10, uma média de 1430,0 \pm 121,5 e $1849 \pm 149,1$, resultados estatisticamente significantes $(p=0,002)$ que representaram um aumento aproximado de $27 \%$ no número de neurônios dos animais queimados.

A distribuição das áreas dos perfis neuronais reativos à técnica da NADH-d pode ser verificada na figura 3.

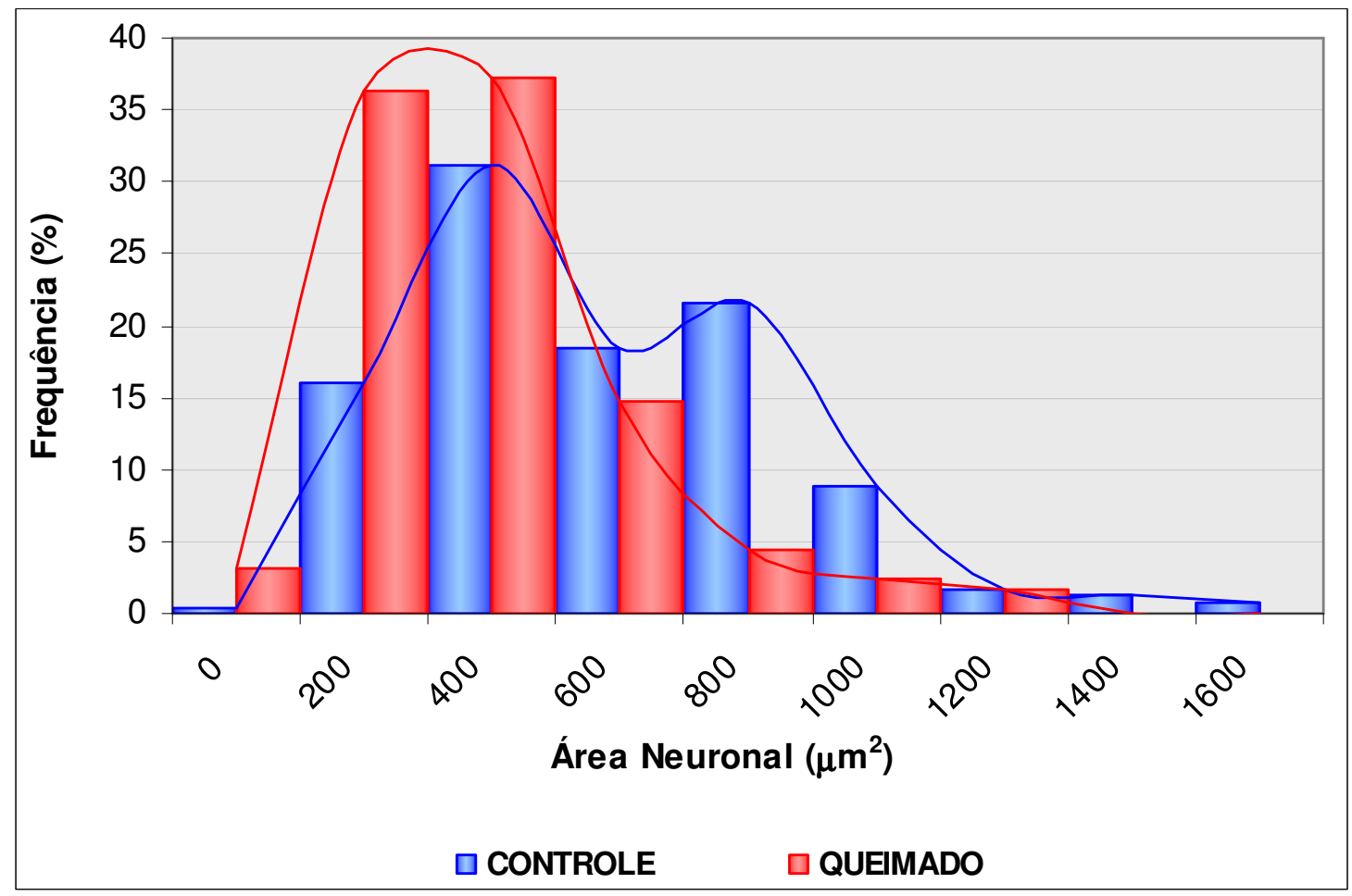

Figura 3. Demonstra a área dos neurônios do estômago de animais dos grupos c10 e q10 evidenciados pela técnica do NADH-d.

A análise do gráfico permitiu verificar que para os animais do grupo c10 a área variou de $198,69 \mu \mathrm{m}^{2}$ a $1658,99 \mu \mathrm{m}^{2}$, com maior concentração (70\%) entre as áreas de $400 \mu \mathrm{m}^{2}$ a $800 \mu \mathrm{m}^{2}$. Nos animais do grupo $\mathrm{q} 10$ as áreas variaram de $143,76 \mu \mathrm{m}^{2}$ a $1362,79 \mu \mathrm{m}^{2}$. A maior concentração de neurônios (73\%) esteve entre $300 \mu \mathrm{m}^{2}$ a $600 \mu \mathrm{m}^{2}$.

Ao analisar a média da área do perfil dos neurônios reativos à NADH-d, verificou-se uma média ( \pm desvio padrão) de $637,25 \pm 280,13 \mu \mathrm{m}^{2}$ para os animais do 
grupo $c 10$ e de $475,41 \pm 214,38 \mu \mathrm{m}^{2}$ para os animais do grupo q10. Esses dados evidenciaram uma diminuição significativa $(p<0,001)$ de $26 \%$ na área do perfil dos neurônios dos animais queimados.

A distribuição das áreas dos perfis neuronais reativos à técnica da NADPH-d pode ser verificada na Figura 4.

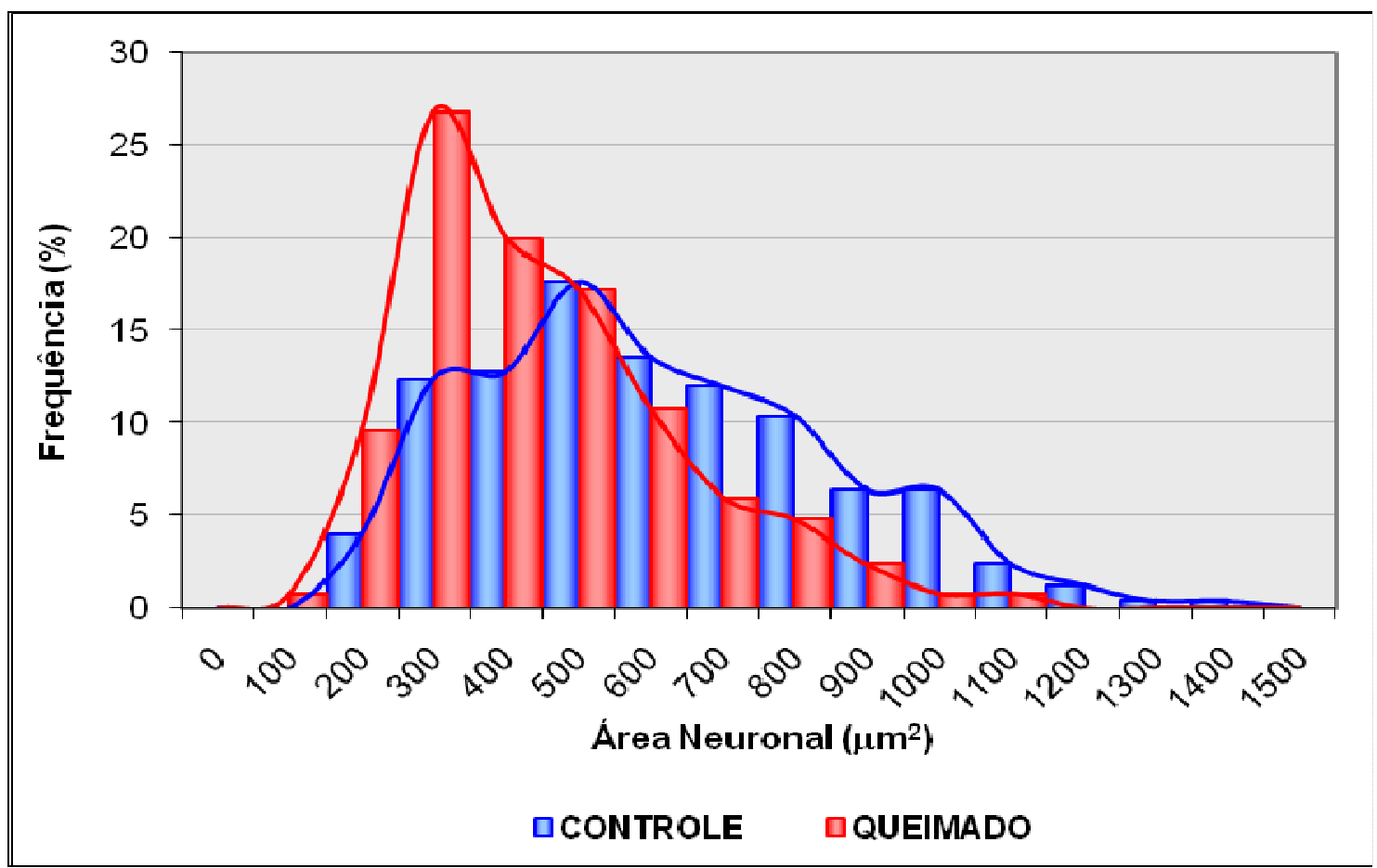

Figura 4. Demonstra a área dos neurônios do estômago de animais dos grupos c10 e q10 evidenciados pela técnica do NADPH-d.

A análise do gráfico permitiu verificar que para os animais do grupo c10 a área variou de $208,69 \mu \mathrm{m}^{2}$ a $1474,41 \mu \mathrm{m}^{2}$, com uma concentração maior (56\%) entre as áreas de $400 \mu \mathrm{m}^{2}$ a $700 \mu \mathrm{m}^{2}$. Nos animais do grupo q10, as áreas variaram de $187,51 \mu \mathrm{m}^{2} 1157,52 \mu \mathrm{m}^{2}$. A maior contração de neurônios (64\%) esteve na faixa de $300 \mu \mathrm{m}^{2}$ a $600 \mu \mathrm{m}^{2}$.

Ao analisar a média da área do perfil dos neurônios nitrérgicos verificou-se uma média ( \pm desvio padrão) de $655,0 \pm 244,8 \mu \mathrm{m}^{2}$ para os animais do grupo c10 e de $499 \pm 187,0 \mu \mathrm{m}^{2}$ para os animais do grupo q10. Esses dados evidenciaram uma diminuição significativa $(p<0,001)$ de $24 \%$ na área do perfil dos neurônios dos animais queimados. 
A análise da mensuração da espessura da mucosa do estômago dos ratos dos grupos c10 e q10, podem ser verificadas na figura 5.

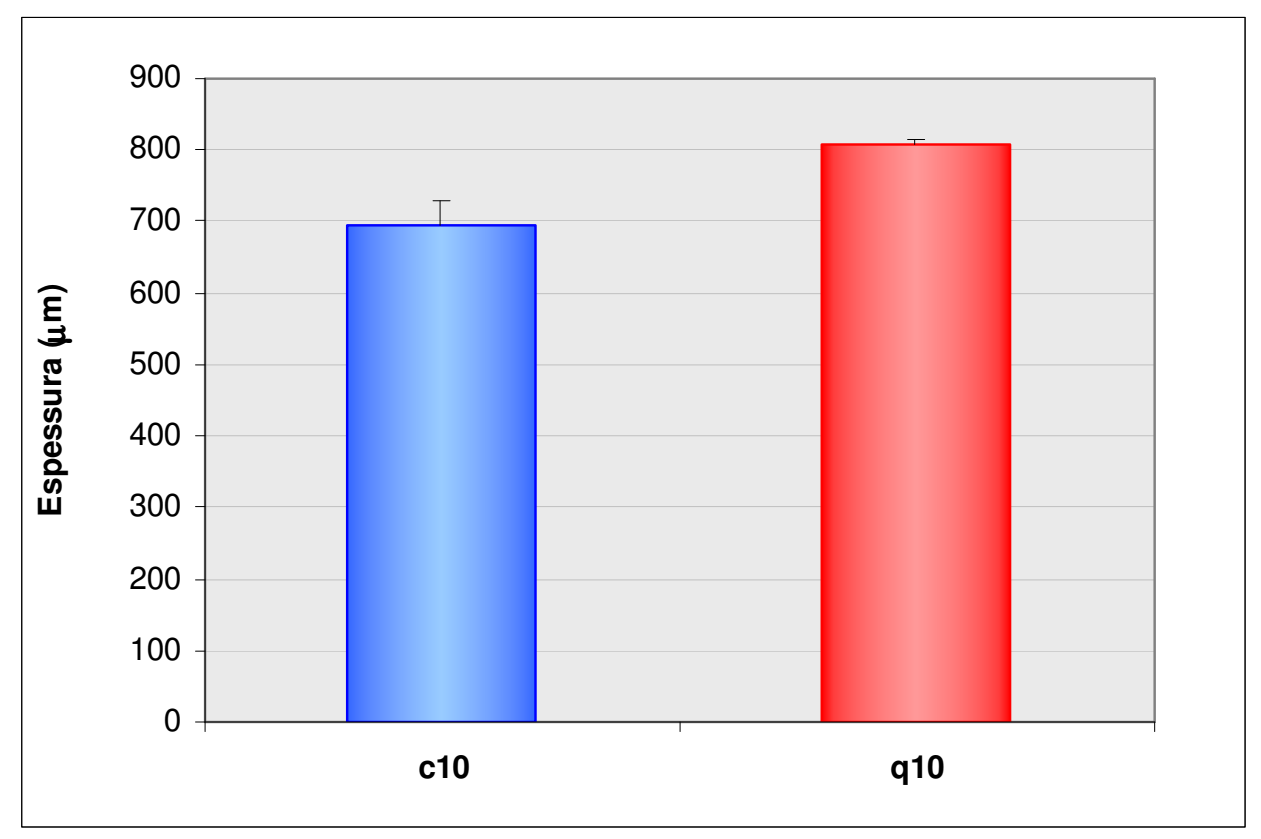

Figura 5. Demonstra a espessura $(\mu \mathrm{m})$ da mucosa gástrica dos animais dos grupos c10 e q10.

A análise do gráfico permitiu verificar que há um aumento na espessura da mucosa no grupo q10, onde a média ( \pm desvio padrão) foi de $808,36 \pm 7,73$ e no grupo c10 a média ( \pm desvio padrão) foi de 696,16 $\pm 32,80(p=0,004)$. Houve um aumento de $22 \%$, na espessura da mucosa

\subsection{Análise qualitativa}

Ao se avaliar os espécimes dos grupos $\mathrm{C} 10$ e q10 submetidos às diferentes técnicas, verificaram-se diferenças importantes entre os mesmos. Assim, muito embora com a técnica da NADH-d os neurônios de diferentes tamanhos tenham sido evidenciados em ambos os grupos (c10, q10), a diferença de intensidade foi uma constante preferencialmente no que se refere aos neurônios pequenos que apresentaram uma menor intensidade no grupo experimental (q10) (Figura 6).

Na reação à NADPH-d chamou a atenção o fato de diversos neurônios do grupo experimental apresentarem um contorno crenado de seu citoplasma, o que muito raramente foi observado nos neurônios do grupo controle (Figura 7). 
Relativamente à reação da $\mathrm{AChE}$ foi nítida a maior quantidade de neurônios de diferentes tamanhos reativos nos gânglios dos animais do grupo controle (c10). Nos animais queimados (q10) aparentemente foram os neurônios de tamanho pequeno que se mostraram intensamente reativos, o que se comprova com a Figura 8 , onde os contornos dos neurônios médios e grandes não reativos podem ser bem observados.

As técnicas imunohistoquímicas para 0 VIP e a SP analisadas conjuntamente permitiram verificar que nos gânglios dos animais c10 a imunorreatividade foi muito expressiva, contrastando sobremaneira com aquela dos animais queimados (q10). Nestes foi possível verificar uma densidade muito menor de varicosidades relativas ao VIP e à SP. (Figura 9 e 10).

Relativamente à mucosa do estômago verificou-se sob microscopia eletrônica de varredura um aumento aparente da sua espessura nos animais do grupo q10; estruturalmente, não foram notadas diferenças significativas entre 0 grupo controle e o grupo experimental.(Figura 11). Isto foi confirmado com a mensuração da mucosa em imagens obtidas de lâminas coradas pela técnica HE.(Figuras 11 e 15)

Os gânglios são envoltos por tecido conjuntivo rico em fibras colágenas e escassas fibras elásticas, desta forma, a técnica histológica para evidenciação de colágeno foi a de picro sírius, que analisada sobre microscópio com luz polarizada, observou-se um aumento do colágeno do tipo 3 no gânglio mioentérico do grupo q10 (Figura 12). Na mucosa gástrica, resultado parecido foi observado, onde pode-se constatar um aumento de fibras apresentando maior quantidade de colágeno tipo 3 no grupo q10 (Figura 13). Para a observação de tecido elástico no plexo mioentérico foi utilizada a técnica de Verhoeff, onde apresentou um discreto aumento no grupo q10 (Figura 14). 

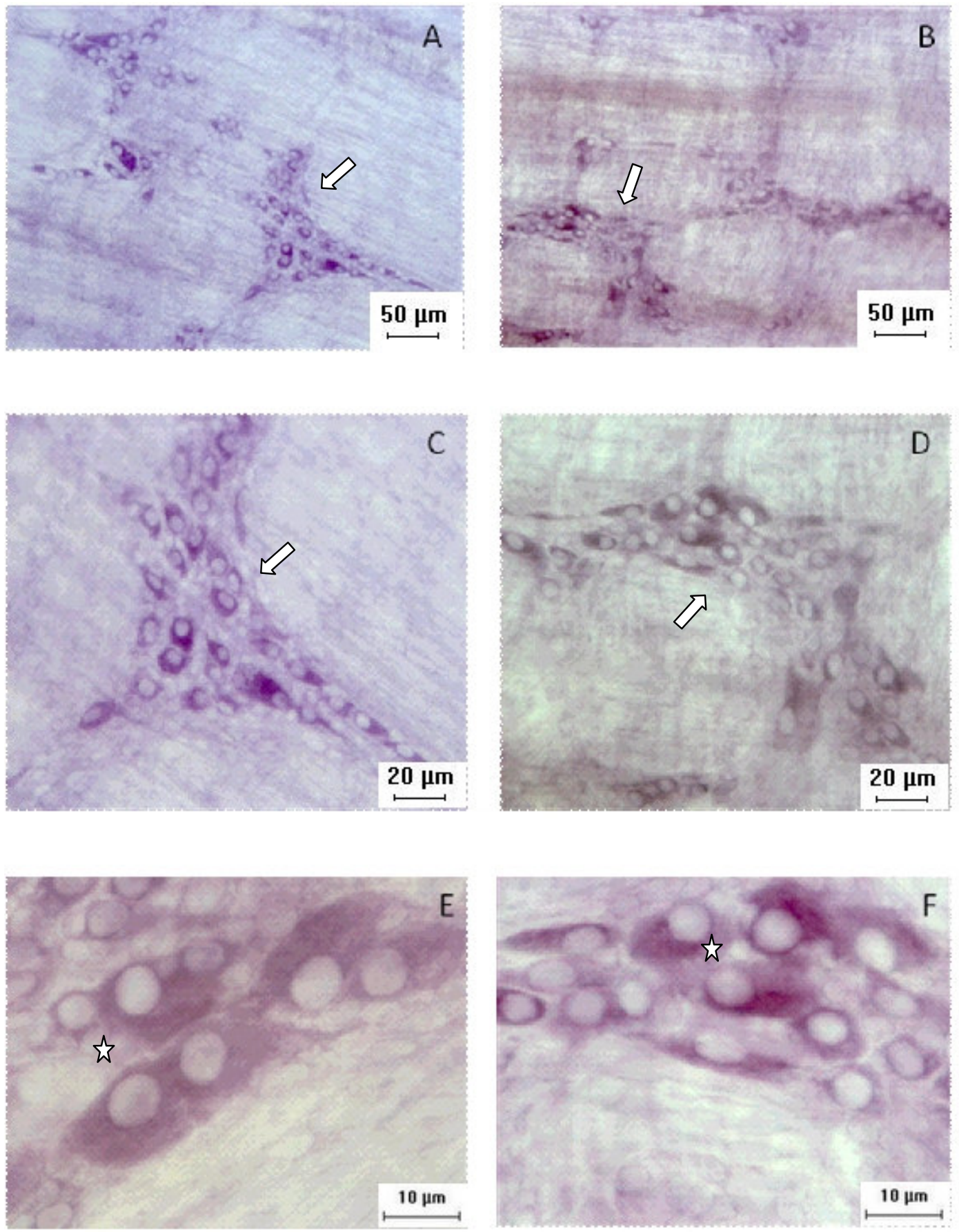

Figura 6. Fotomicrografias de preparados de membrana do estômago de rato dos grupos c10 (A, C, E) e q 10 (B, D, F) evidenciando gânglios com neurônios mioentéricos NADH-d positivos. Setas indicam diferença de intensidade apresentada pelos grupos estudados. Estrela indica no gânglio o número maior de neurônios grandes no grupo c10 e neurônios menores no grupo q10. 

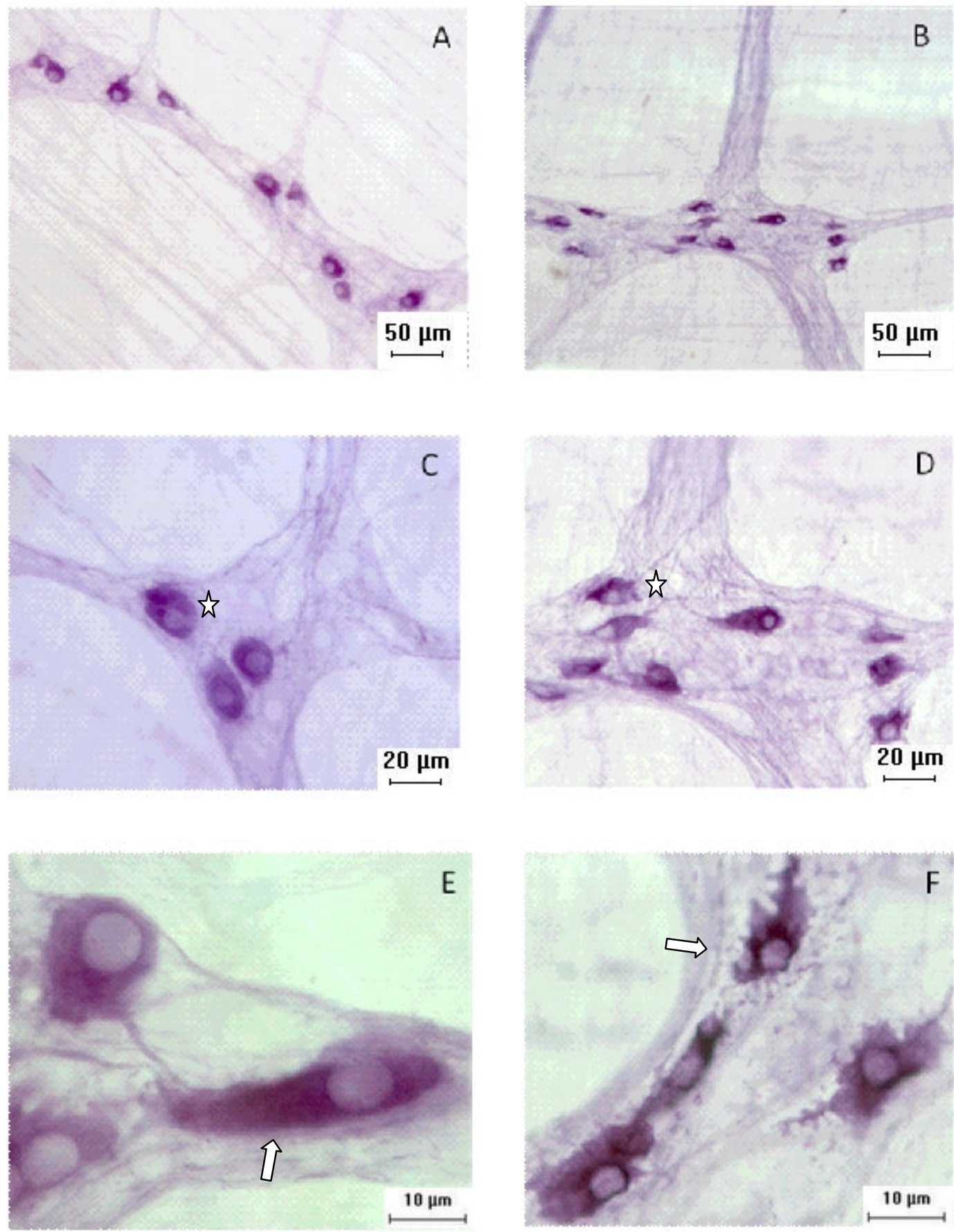

Figura 7. Fotomicrografias de preparados de membrana do estômago de rato dos grupos c10 (A, C, E) e q 10 (B, D, F) evidenciando gânglios com neurônios mioentéricos NADPH-d positivos. Setas indicam contorno regular citoplasmático nos neurônios do grupo c10 e contorno irregular no grupo q10. Estrelas indicam gânglio com maior número de neurônios marcados no grupo q10. 

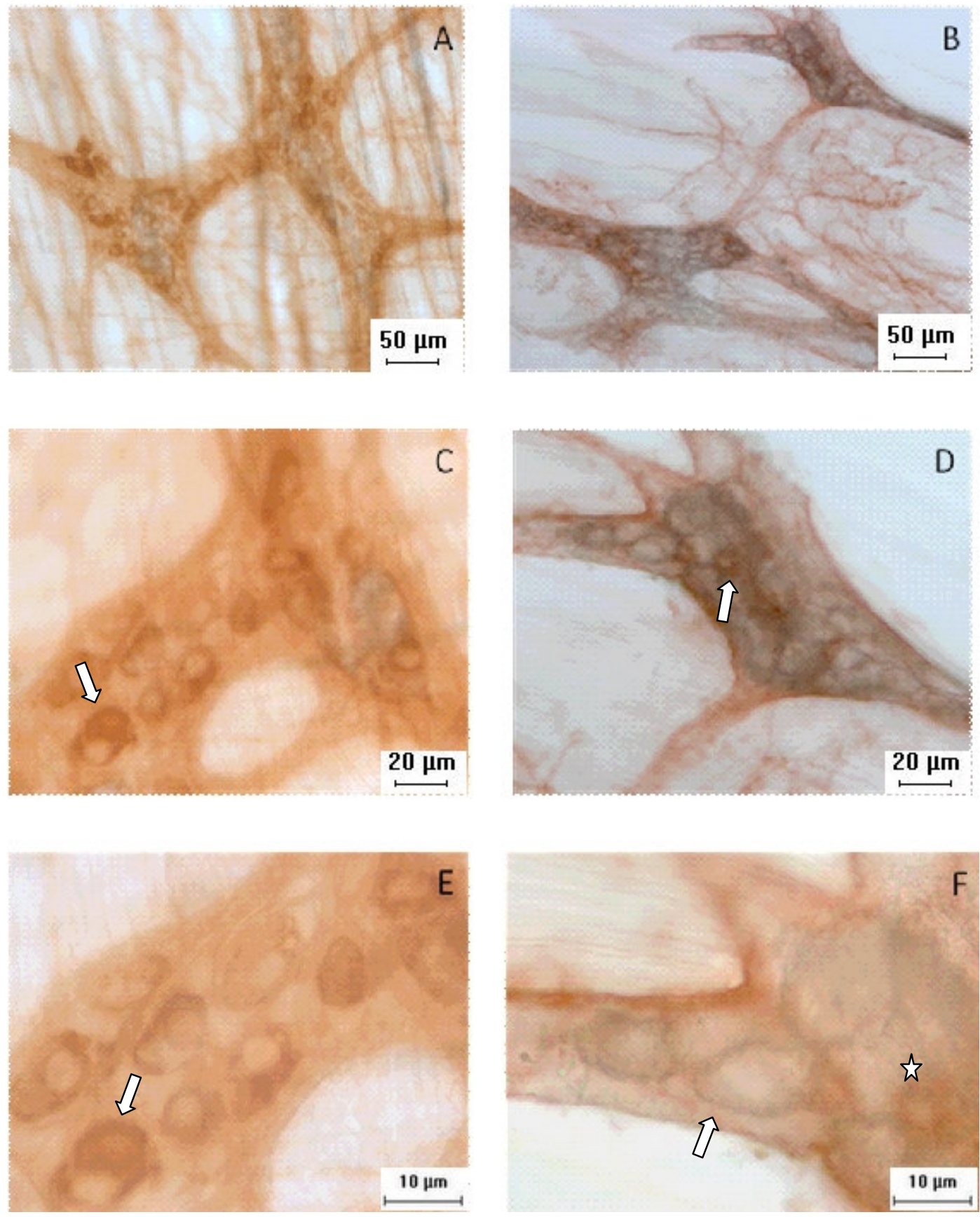

Figura 8. Fotomicrografias de preparados de membrana do estômago de rato dos grupos c10 (A, C, E) e q 10 (B, D, F) evidenciando gânglios com neurônios mioentéricos AChE-r. Setas indicam contorno regular citoplasmático nos neurônios do grupo c10 e contorno irregular no grupo q10. Estrela indica no grupo q10, apenas neurônios pequenos apresentando reatividade ao marcador neuronal. 

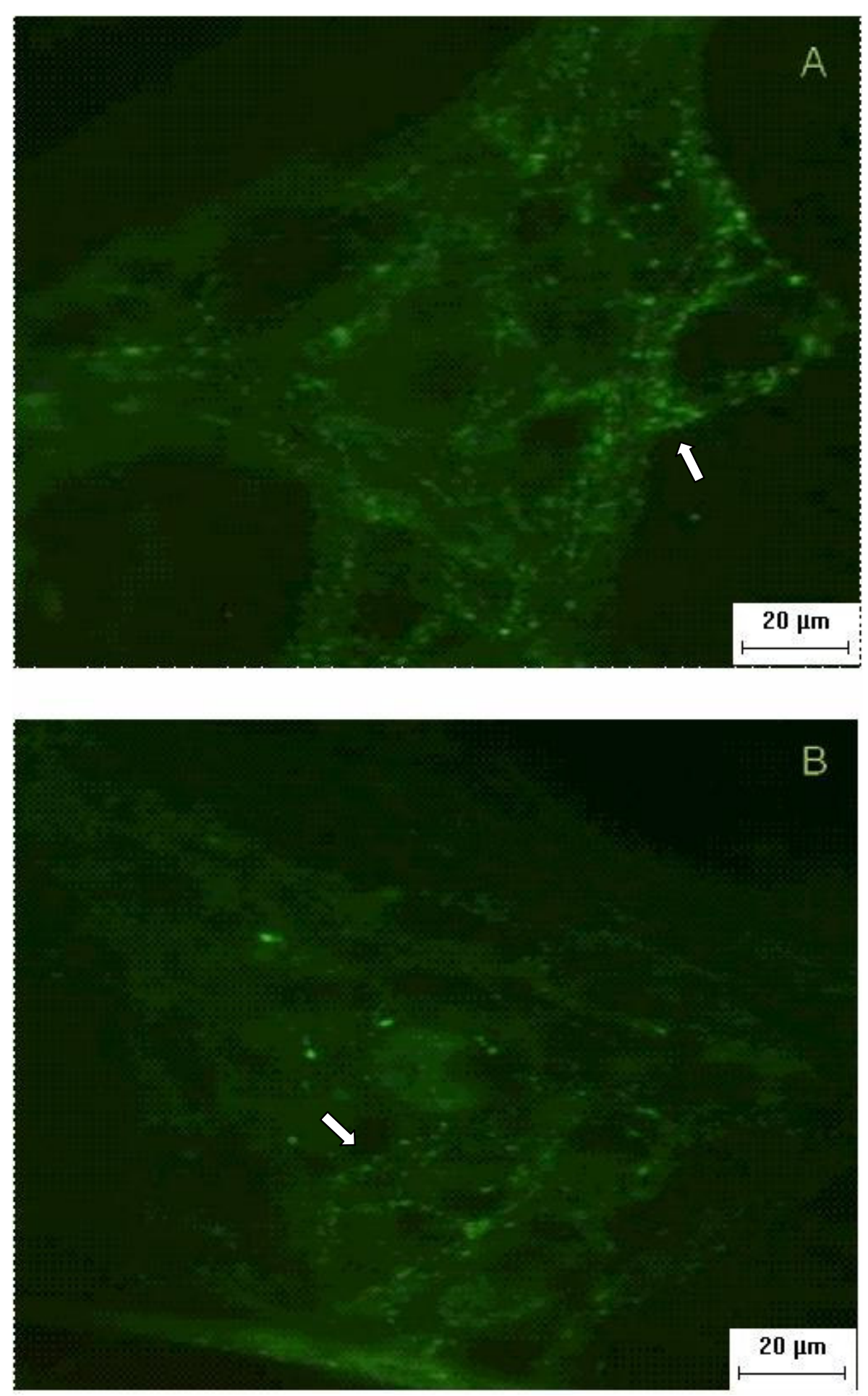

Figura 9. Demonstra gânglio com neurônios imunorreativos ao VIP. A - grupo c10, B - grupo q10; Setas indicam varicosidades maiores e mais fortemente reativas em $A$ do que em B. 
1

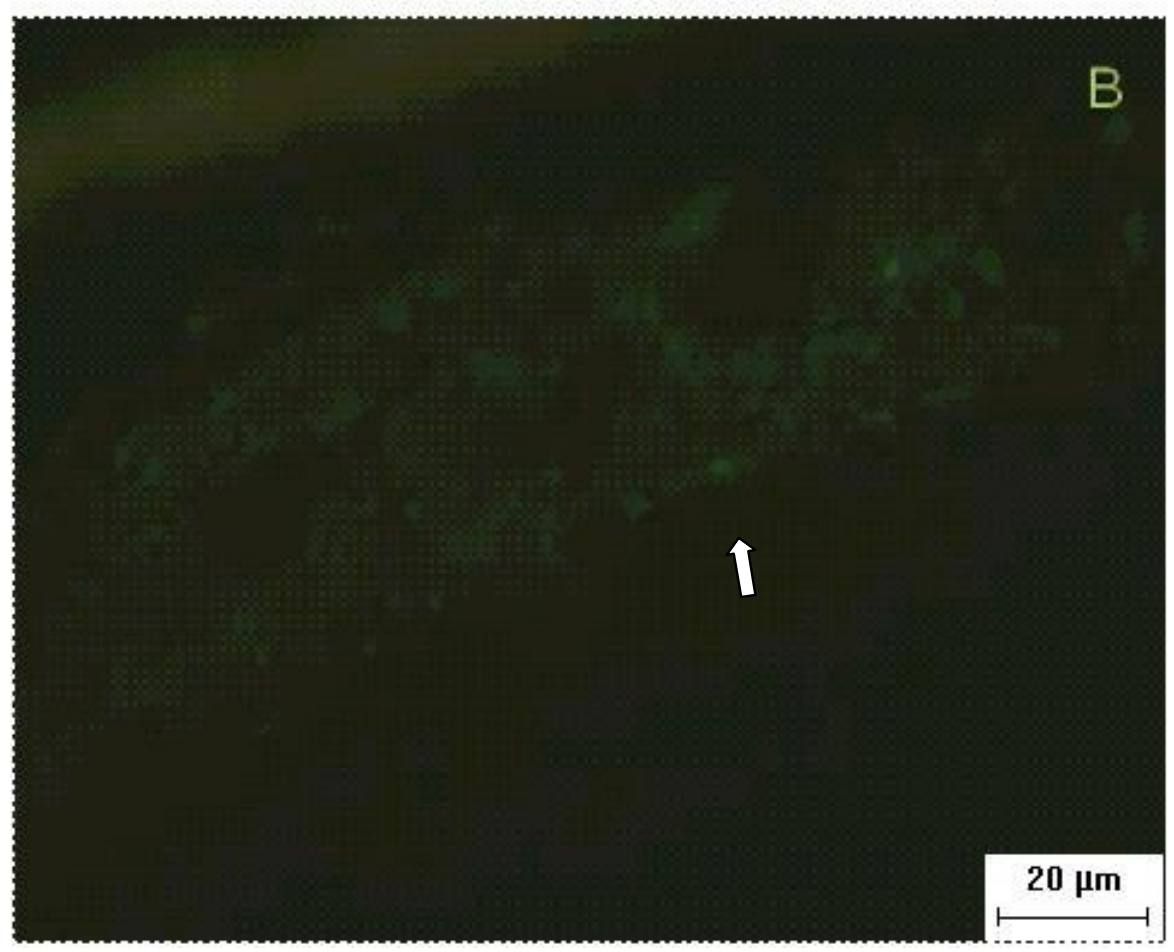

Figura 10. Demonstra gânglio com neurônios imunorreativos a SP. A - grupo c10, B - grupo q10; Setas indicam varicosidades gânglio com imunoreatividade em $A$, enquanto que em $\mathrm{B}$ a imunoreatividade é muito baixa. 

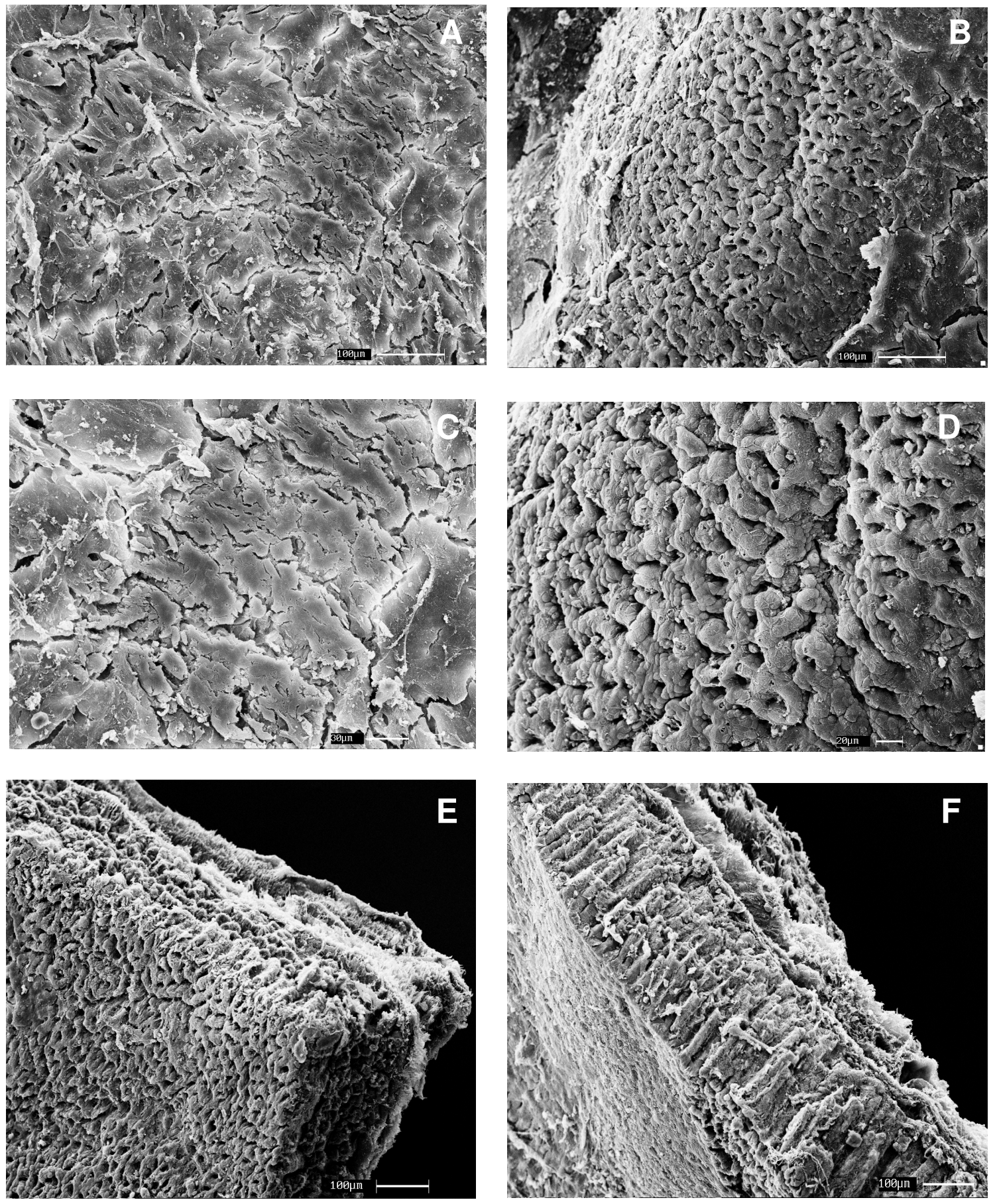

Figura 11. Fotomicrografia da mucosa gástrica evidenciada pela técnica de Microscopia Eletrônica de Varredura, (A; C; E) evidenciam mucosa gástrica de animais pertencentes ao grupo c10 e (B; D; F) evidenciação da mucosa de animais do grupo q10. 

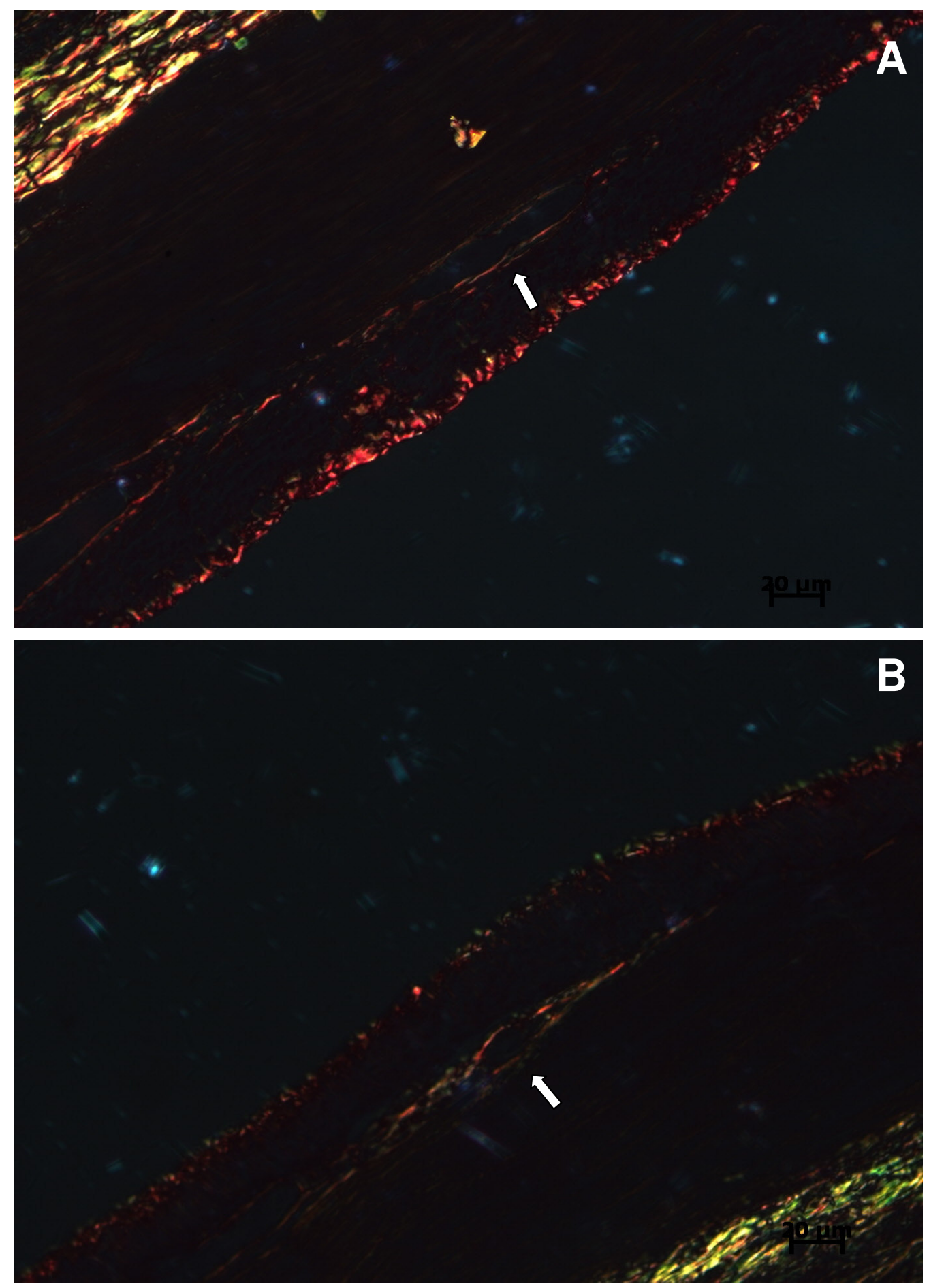

Figura 12. Demonstra o gânglio mioentérico evidenciado pela técnica histológica de picrosirius e sobre luz polarizada. As setas indicam o gânglio com contorno de fibras colágenas. A - grupo c10 e B - grupo q10. No grupo q10 houve aumento de fibras colágenas ao redor do gânglio. 

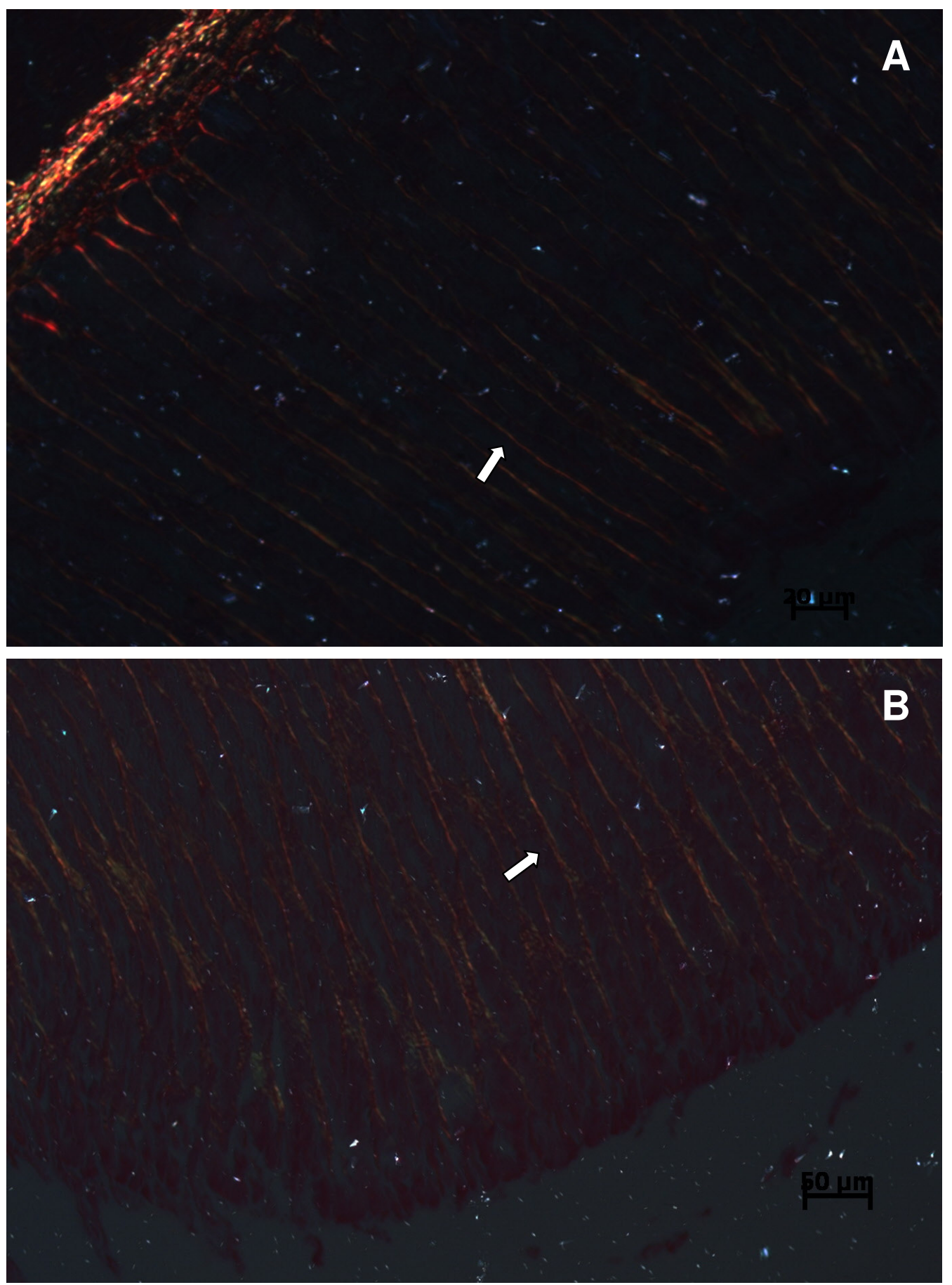

Figura 13. Demonstra a mucosa gástrica evidenciada pela técnica histológica de picro-sirius sobre luz polarizada A - grupo c10 e B - grupo q10. As setas indicam fibras colágenas de maior espessura em B. 

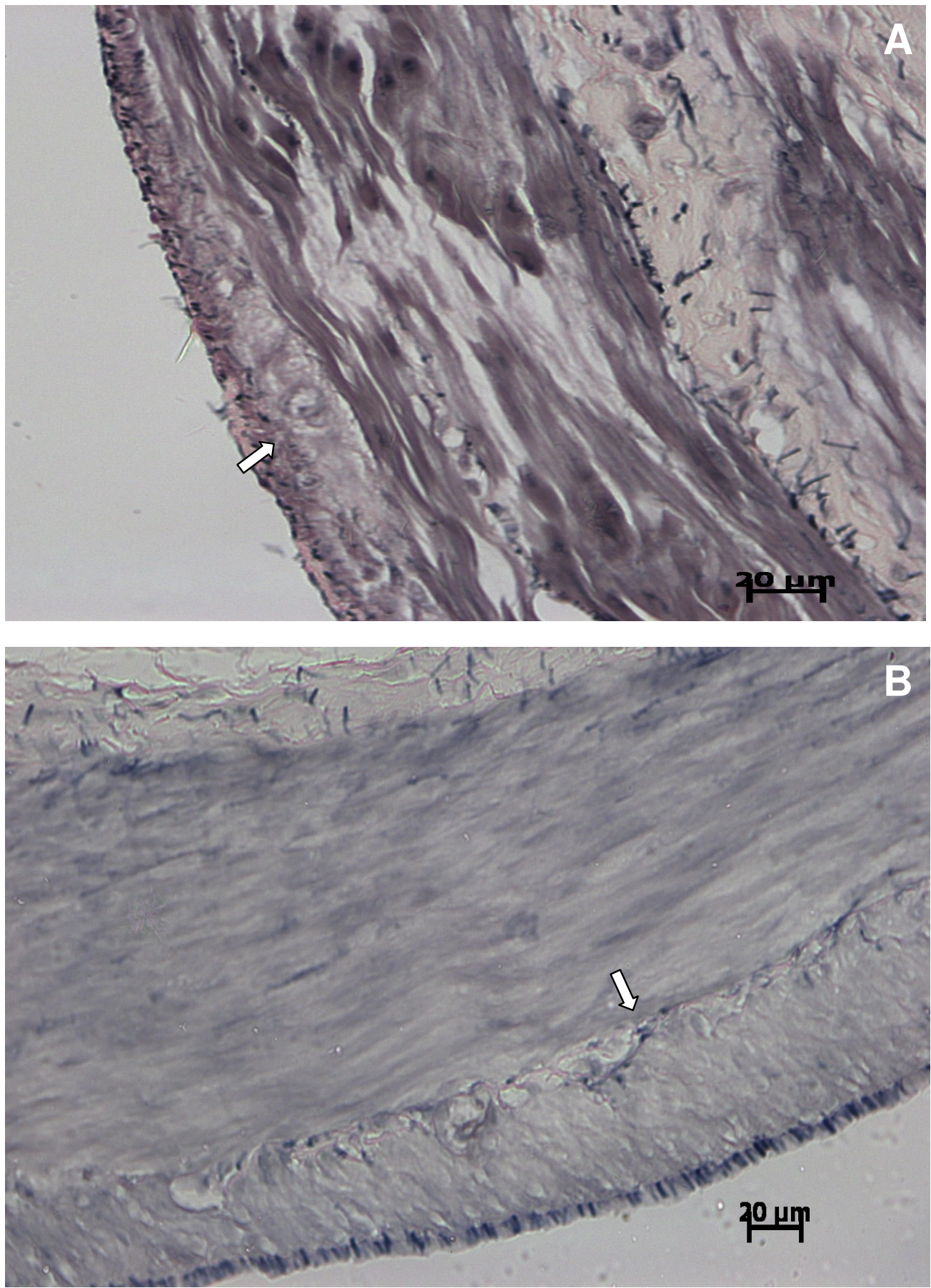

Figura 14. Demonstra o gânglio mioentérico evidenciado pela técnica histológica de verhoeff. As setas indicam o gânglio com pequena quantidade de fibras elásticas A - grupo c10 e B - grupo q10. No grupo q10 houve aumento de fibras elásticas no gânglio. 

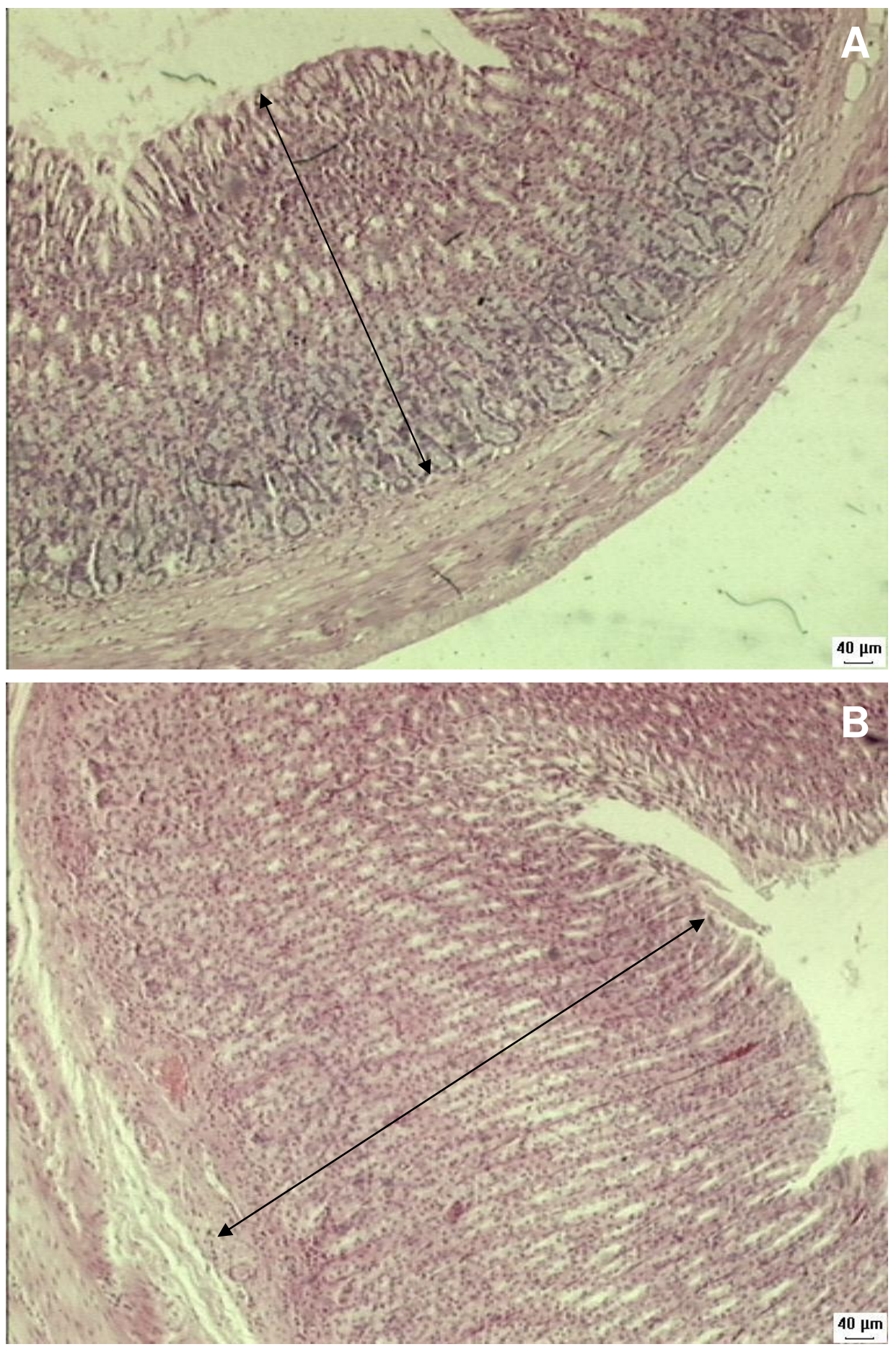

Figura 15. Demonstra o gânglio mioentérico evidenciado pela técnica histológica de hematoxilina-eosina (HE). As setas indicam a espessura da mucosa gástrica. A - grupo c10 e B - grupo q10. No grupo q10 houve aumento da espessura da mucosa. 
5 DISCUSSÃO 
O modelo para que realizasse a LTC no animal, foi o mesmo empregado por Walker e Mason (1986), após a anestesia e tricotomia houvesse a lesão em água à $85^{\circ} \mathrm{C}$, de aproximadamente $30 \%$ do corpo do animal, isto com base no peso corporal. Fez-se a tricotomia devida à necessidade de expor a área a ser queimada, para que a LTC fosse significativa, pois devido à presença de pêlos a água não alcançaria a pele.

Devido a LTC pode-se observar que no grupo q10, houve perda significante de peso corporal com pequena recuperação posterior, já no grupo c10 a diminuição do peso foi observado, isto devido ao estresse da anestesia e tricotomia, com posterior restabelecimento do peso, bem como ganho da massa corpórea. Com esses resultados pode-se crer que o emprego do modelo da LTC demonstrou efeitos diretos no trato gastrintestinal.

De acordo com Irwin (1931), os neurônios mioentéricos na túnica muscular do trato gastrintestinal encontram-se agrupados em gânglios que se unem por meio das fibras nervosas, formando uma malha ou uma rede ganglionar. Disposição neural semelhante foi também observada nos preparados de membrana do estômago dos dois grupos analisados neste estudo.

Para verificar os efeitos da LTC sobre os neurônios mioentéricos NADH-dr, que permite evidenciar $80 \%$ da população total de neurônios no plexo mioentérico, conforme descrito por Young et al.(1993) e NADPH-dr, que evidencia neurônios potencialmente nitrérgicos, ou seja, que sintetizam NO realizou-se a quantificação desses neurônios, bem como a mensuração do perfil celular de 50 neurônios mioentéricos NADH-dr e NADPH-dr por preparado de membrana perfazendo um total de 250 neurônios por grupo (c10 e q10) e por técnica histoquímica empregada.

Pesquisas anteriores indicaram que o número e o tamanho dos neurônios diferem significativamente entre as regiões aglandular e glandular do estômago de ratos. Sendo assim, no presente trabalho foi estudado somente a região glandular, devido a apresentar um revestimento interno mucoso espesso diferente da região aglandular, que internamente apresenta uma delgada membrana serosa e não apresenta glândulas.

A análise quantitativa de neurônios NADH-dr na totalidade da região glandular, demonstrou uma diferença na quantidade neuronal em diferentes regiões (OLIVEIRA et al., 2000; FREGONESI et al., 2001). Porém neste trabalho foi feita uma análise generalizada, sem dividir a pate estudada em regiões, desta maneira, 
ocorreu um aumento de 25\% ( $p<0,001)$ no número de neurônios NADH-dr no grupo q10, comparado ao c10.

Estes resultados concordam com pesquisas feitas em outros modelos experimentais, como as vistas por Natali (1993) e Brandão (1998), que demonstraram um maior número de células nervosas no plexo mioentérico durante a desnutrição. E também com os resultados encontrados por Furlan et al. (1999), onde demonstraram um aumento na densidade de neurônios NADH-dr em ratos submetidos ao diabetes.

A técnica da NADH-d é inspecífica do ponto de vista do fenótipo neurotransmissor dos neurônios evidenciados, baseia-se na condição bioquímica da célula: o termo NADH-d é genérico para enzimas capazes de oxidar NADH na presença de um aceptor artificial de elétrons (DORLAND et al., 1994). O aumento no número de neurônios NADH-dr no estômago dos animais do grupo q10 sugere uma alteração no metabolismo neuronal tornando um grupo maior de neurônios mioentéricos reativos à técnica nas condições empregadas.

Os neurônios que sintetizam NO, tanto no sistema nervoso central quanto no periférico, podem ser visualizados pelo emprego da histoquímica NADPH-d (DAWSON et al., 1991; BELAl et al., 1992; JOHNSON et al., 1998) e compõe uma fração significativa da população neuronal mioentérica total em qualquer segmento do tubo digestório (FURLAN et al., 1999). Desta forma a estrutura do plexo evidenciado pelo NADPH-dr foi semelhante à aquela relatada em outras investigações (BELAl et al., 1992; WESER et al., 1999), em que não só os corpos celulares mas também os feixes nervosos foram visualizados.

O número de neurônios mioentéricos NADPH-dr aumentou 27\% no grupo q10 comparado com grupo c10. Desta maneira percebeu-se um aumento no número de neurônios em animais que foram queimados, porém a sua aparência deixa evidente que há algo nessas células nervosas que está comprometido, visto a aparência crenada do contorno citoplasmático. Sendo assim, a função desempenhada por esses neurônios que é a inibição do músculo liso no estômago, que é essencial para a progressão das ondas peristálticas e para o controle da passagem do conteúdo de um segmento digestório para outro (COSTA e BROKES, 1994; KUTCHAI, 2000), pode ter sido alterado.

Em se tratando de perfil neuronal, a presente pesquisa, revelou diferenças significativas na área dos perfis neuronais nos animais dos grupos c10 comparados 
ao grupo q10, onde neste último foram menores, tanto nos avaliados pelas técnicas histoquímicas do NADH-d como do NADPH-d.

Dados dos estudos de Molinari et al., 2004, concordam com os resultados deste trabalho, onde ao estudar os efeitos do alcoolismo crônico nos neurônios NADH-d do plexo mioentérico do estômago de ratos, observou uma diminuição no número de neurônios grandes e aumento de neurônios pequenos com prevalência de neurônios de tamanho médio.

Corrobora também com estes dados Maifrino, (1996), que ao analisar os aspectos da infecção no plexo mioentérico do colo de camundongos pelo Trypanosoma cruzi, onde verificou uma diminuição do tamanho do corpo celular nos animais do grupo infectado.

Através da MEV, e posterior confirmação morfométrica, quando se confirmou uma maior espessura da mucosa gástrica para o grupo q10, pode-se inferir um comprometimento do esvaziamento gástrico o que, supostamente, levaria a um aumento na concentração ácida no interior da víscera, colaborando para o aparecimento de ulcerações. Muito embora ulceraões não tenham sio detectadas no período estudado, os dados permitem concordar com Alican et al. (1995), que verificaram uma concentração de soluções ácidas e peptonas significativamente maiores no interior do estômago de ratos que sofreram LTC e com as afirmações de Mochizuki et al., 1984; Deitch, 1990; Varedi et.al., 1999, no ntestino delgado, onde a LTC resultou em alterações morfológicas, funcionais e grandes alterações na mucosa. Na região das criptas, as células se apresentam linearmente com diferentes potenciais de proliferação e são sensíveis à LTC, com alterações na posição e proliferação celular após o estresse. (IJIRI e POTTEN, 1983; IJIRI e POTTEN 1987; POTTEN et.al., 1994)

Vários autores têm relatado a dilatação e a hipotonia gástrica com diminuição no esvaziamento gástrico (CESARINI et al., 1997; CAMILLERI, 2002; De BLOCK et. al., 2002). Sendo o NO um neurotransmissor inibitório, quando aumentado poderia intensificar o relaxamento da musculatura gástrica, com conseqüente diminuição no esvaziamento favorecento a gastroparesia. Faz-se necessário, entretanto, investigar se a gastroparesia decorre de um aumento excessivo da produção de NO ou se é a redução da atividade colinérgica que causa a hipomibilidade, ou ainda se os dois fatores se somam para produzir os sintomas. Cesarini et. al. (1997) relatam melhora dos sintomas com uso de agentes colinérgicos, por outro lado, em humanos, os 
efeitos de um doador de NO sobre o esvaziamento gástrico foi avaliado, sendo observada a inibição da motilidade pilórica com diminuição do esvaziamento gástrico (SUN et. Al., 1998). Kuiken et al. (2002) administrando um inibidor da óxido nítrico sintase em humanos saudáveis, observaram diminuição do volume fúndico basal após refeição. Os autores concluem que o NO está envolvido na manutenção do tônus fúndico e no relaxamento fúndico induzido pelo alimento. Coulie et. al. (1999) relacionam a manutenção do tônus fundico com um balanço na ativação de vias colinérgicas e nitrérgicas em gatos.

Varedi et al. (2000) concluiu em seus estudos no intestino delgado de ratos, que a LTC, induz à apoptose nas regiões proliferativas e uma diminuição da atividade mitótica nas criptas, estas regiões são de grande importância para a manutenção da homeostase epitelial (POTTEN 1991; POTTEN 1997). Observaram também uma elevação na permeabilidade gastrintestinal o que pode contribuir para a translocação de bactérias e endotoxinas associadas através da linfa mesentérica, o que pode aumentar o risco de septicemia.

Sendo assim, na presente pesquisa acredita-se que o esvaziamento gástrico foi comprometido devido a uma soma de fatores, onde apesar do aumento dos neurônios NADPH-dr, a expressão do VIP, um neurotransmissor que associado ao NO causa inibição da musculatura lisa, diminuiu, indicando um hipotonismo gástrico. Da mesma maneira, a imunoreatividade da SP foi diminuída, este neurotransmissor atua também na estimulação da contração da musculatura lisa e de secreção de substâncias. Desta forma a gastroparesia resultou em ulcerações na mucosa gástrica.

A constituição morfológica de tecido conjuntivo com fibras colágenas envolvendo o gânglio mioentérico com escassas fibras elásticas foi observada neste trabalho. Resultado semelhante foi obtido por Oliveira et. al. (2000) ao estudar o estômago de ratos, essa disposição e constituição morfológica é também descrita em galinha (GABELLA e HALASY, 1987), e em patos (MOLINARI et al., 1994). O aumento de fibras colágenas e no grupo q10 deve ser um efeito protetor no gânglio e também na mucosa onde foi densamente agredida. 

CONCLUSÕES 
A análise dos resultados relativos à mucosa gástrica e aos componentes do plexo mioentérico do estômago de ratos submetidos à LTC, permite concluir que:

1 A LTC alterou a ingesta alimentar, levando à perda de peso corporal nos animais do grupo q10.

2 O número de neurônios NADH-dr apresentou-se aumentado no grupo q10, o que ocorre devido a uma diminuição do tamanho do órgão devido a uma ação associada de NO, VIP e acetilcolina.

3 O número de neurônios NADPH-dr aumentou no grupo q10; porém, seu contorno citoplasmático apresentou-se crenado, sugerindo comprometimento na síntese dessa substância.

4 Houve diminuição no número de neurônios grandes e aumento de neurônios pequenos no grupo q10 tanto para a reação da NADH-d como da NADPH-d.

5 A reatividade para a AChE foi fraca para a maioria dos neurônios médios e grandes do grupo q10, onde apenas neurônios pequenos aparecem reativos. Além disso, o contorno dos neurônios médios e grandes não apresentou-se bem definido.

6 A imunoreatividade ao VIP e à SP apresentou menor intensidade no grupo q10, sugestivo de menor ação neurotransmissora.

7 A mucosa gástrica apresentou-se mais espesa no grupo q10, o que pode comprometer o esvaziamento gástrico.

8 Ocorreu um aparente aumento de fibras colágenas do tipo I nos animais q10, talvez devido ao aumento da espessura da mucosa observado para esses animais. 
9 Qualitativamente, houve um aumento de fibras colágenas do tipo I e elásticas maduras na cápsula ganglionar dos animais do grupo q10. 


\section{REFERÊNCIAS}


AUERBACH, L. Fernere vorlaufige Mitteilung uber den vervenapparat des Dames. Arch. Pathol. Anat. Physiol., v. 30, p. 457-460,1864.

BEHMER, O.A.; DE TOLOSA, E.M.C.; FREITAS NETO, A.G. Manual de Técnicas para Histologia Normal e Patológica. São Paulo: EDART, 1975.

BELAI, A.; SCHMIDT, H. H. H. W.; HOYLE, C. H. V.; HASSALL, C. J. S.; SAFFREY, M. J.; MOSS, H.; FÖRSTERMANN, U.; MURAD, F.; BURNSTOCK, G. Colocalizations of nitric oxid syntase and NADPH-diaphorase in the myenteric plexus of the rat gut. Neurosci. Lett., v. 143, p. 60-64, 1992.

BERTRAND, P. P.; BORSTEIN, J. C. ATP as a Oytatuve Sensory Mediator: Activation of Intrinsic Sensory Neurons of the Myenteric Plexus via P2X Receptor. J. Neurosci., v. 12, p. 4767-4775, 2002.

BERTHOUD, H. R. Morphological analysis of vagal input to gastrin releasing peptide and vasoactive intestinal peptide containing neurons in the rat glandular stomach. $\mathbf{J}$. Comp. Neurol., v 370, p. 235-242, 1996.

CAMILLERI, M. Advances in diabetic gastroparesis. Rev. Gastroenterol. Dis., v. 2 n. 2, p. 46-56, 2002

CARTER, E. A.; UDALL, J. N.; HIRKHAM, S. E.; WALKER, W. A. Thermal injury and gastrointestinal function. I. Small intestinal nutrient absorption and DNA synthesis. $J$ Burn. Care. Rehabil., v 7, p. 469-474, 1986.

CARTER, E. A.; GONELLA, A.; TOMPIKINS, R. G. Increased transcellular permeability of rat small intestine after thermal injury. Burns. v 18, p. 117-120, 1992.

CESARINI, P. R.; FERREIRA, S. R. G.; DIB, S. A. Gastroparesia diabética. Rev. Assoc. Med. Bras., v.43 n.21, 1-8, 1997.

COSTA, M.; BROOKES, S. J. H. The enteric nervous system. Am. J. Gastroenterol., v. 89, n. S129-S137, 1994.

\footnotetext{
"De acordo com:

ASSOCIAÇÃO BRASILEIRA DE NORMAS TÉCNICAS. NBR 6023: Informação e documentação: referências: elaboração. Rio de Janeiro, 2002.
} 
COULIE, B.; TACK, J.; SIFRIM, D.; ANDRIOLI, A.; JANSSENS, J. Role of nitric oxide in fasting gastric fundus tone and in 5-HT receptor mediated relaxation of gastric fundus. Am. Phisiolol. Soc., v. 276, n.2Pt1, p. G373-377, 1999

CURRERI, P. W.; LUTERMAN, A. Burns In: Schwartz SI. Princiles of Surgery., v 1, p. 302, 1986.

CURRO, D.; PREZIOSI, P. Non-adrenergic non-cholinergic relaxation of the rat stomach. Gen. Pharmacol., v. 31, p. 697-703,1998.

DAWSON, T. M.; BREDT, D. S.; FOTUHI, M.; HWANG, P. M.; SNYDER, S. H. Nitic oxide syntase and neuronal NADPH-diaphorase are identical in brain and peripheral tissues. Proc. Natl. Acad. Sci., v, 88, p. 7797-7801, 1991.

De BLOCK, C. E. M.; De LEEUW, I. H.; PELCKMANS, P. A.; CALLENS, D.; MADAY, E.; VAN GAAL, L. F. Dalayed gastric emptying and gastric autommunity in type 1 diabetes. Diabetes Care., v. 25, n. 5, p. 912-917, 2002.

DEITCH, E. A. Intestinal impermeability is increased in burns patients shortly after injury. Surg., v. 107, p. 411-416, 1990.

DEITCH, E. A.; RUTAN, R.; WAYMACK, J. P. Trauma, shock, and gut translocation. New Horiz 4, p. 289-299, 1996.

De-SOUZA, D. A.; MARCHESAN, W. G.; GREENE, L. J. Epidemiological data and mortality rate of patients hospitalized with burns in Brazil. Burns. v 24, p. 433-438, 1998.

DORLAND, W. A. N. Dorland's Illustrated Medical Dictionary. W. B. Sanders, Philadelphia, 1994.

EZZELL, R. M.; CARTER, E. A.; YARMUSH, M. L.; TOMPIKINS R. G. Thermal injury-induced changes in the rat intestine brushborder cytoskeleton. Surg. v 114, p. 591-597, 1993.

FINE, J.; FRANK, E.; HERBERT, R.; RUTENBERG, S.; SCHWEINBURG, F. The bacterial factor in traumatic shok. N. Engl. J. Med. V. 260, p. 214, 1959. 
FREGONESI, C. E. P. T.; MIRANDA-NETO, M. H.; MOLINARI, S. L. Estudo morfológico e quantitativo dos neurônios do plexo mioentérico do corpo do estômago de Rattus norvegicus. Acta Scient. v. 20, p. 221-224, 1998.

FREGONESI, C. E. P. T. MIRANDA-NETO, M. H.; MOLINARI, S. L.; ZANONI, J. N. Quantitative study of the myenteric plexus of the stomach of rats with streptozotocininduced diabetes. Arq. Neuropsi.,v. 59,n. 1, p. 50-53, 2001.

FURLAN, M. D. P.; MIRANDA-NETO, M. H.; SANT'ANA, D. M. G.; MOLINARI, S. L. Number and size of myenteric neurons of the duodenum of adult rats with acute diabetes. Arq. Neuropsi. v. 57, p. 740-745, 1999.

FURNES, J. B.; COSTA M. The Enteric Nervous System. England: Chu. Liveng., 1987.

FURNESS, J. B. Types of neurons in the enteric nervous system. J. Autonom. v. 81, p. 87-96, 2000.

FURNESS, J. B. Novel gut afferents: Intrinsic afferent neurons and intestinofugal neurons. Auton. Neurosc. Basic and Clinica, 2006.

GABELLA, G.; HALASY, K. On the nerve plexus of the chicken gizzard. Anat Embriol. v. 177, p. 97-103, 1987.

GOSAIN, A.; GAMILLI, L. R. Role of the Gastrointestinal Tract in Burns Sepsis. J. Burn Care Rehabil. v. 26, p. 85-91, 2005.

HENLE, J. Handbuch der system atischen Anatomie des Menschen. Band III, Abt 2 Nervenlehre, F Vieweg und Sohn, Braunschweig, 1871.

HOLZER-PETSCHE, U.; SEITZ, H.; LEMBECK, F. Effect of capsaicin on gastric corpus smooth muscle of the rat in vitro. Eur. J. Pharmacol. v.162, p. 29-36, 1989.

IBEBUNJO, C.; MARTYN, J. A. J. Disparate dysfunction of skeletal muscles located near and distant from burn site in rat. Muscle \& Nerve. v. 24, p. 1283-1294, 2001.

IJIRI, K.; POTTEN, C. S. Response of intestinal cells of differing topographical and hierarchical status to ten cytotoxic drugs and five sources of radiation. Br. J. Câncer. v. 47, n. 2 , p. $175-185,1983$. 
IJIRI, K.; POTTEN, C. S. Further studies on the response of intestinal crypt cells of different hierarchical status to eighteen different cytotoxic agents. Br. J. Câncer. v. 55, n. 2, p. 113-123, 1987.

IRWIN, D. A. The antomy of Auerbach's plexus Am. J. Anat. v. 49, 141-166, 1931.

KEITH, K. H. Gastric emptying of liquid and solids: roles of proximal and distal stomach. Am. J. Physiol. v. 239, p. G71-G76, 1980.

JOHNSON, R. J. R.; SHEMANN, M.; SANTER, R. M.; COWEN, T. The effects of age on the overall population and on subpopulations of myenteric neurons in the rat small intestine. J. Anat. v.192, p. 479-488, 1998

KOO, M. W. L.; OGLE, C. W.; CHO, C. H. The effect of cold-resistaint stress on gastric emptyng in rats. Pharmacol. Biochem. Behav. v. 23, p. 969-972, 1985.

KUIKEN, S. D.; VERGEER, M.; HEISTERKAMP, S. H.; TYTGAT, G. N. J.; BOECKXTAENS, G. E. E. Role of nitric oxide in gastric motor and sensory functions un healthy subjects. Gut. v. 51, n. 2, p. 677-680, 2002.

KUTCHAI, H. C. Motilidade gastrointestinal In: Berne R. m.; Levy M. N. (Eds), Fisiologia. Guanabara koogan, Rio de Janeiro, p. 555-580, 2000.

LANGLEY, J. N. The autonomic nervous system, part 1. Heffer, Combridge, 1921

LANGLEY, J. N. The sympathetic and other related system of nerves. In: Schaffer E A (ed) Text book of physiology. Pentland, Edinburgh p. 616-696, 1990.

LEFEBVRE, R. A.; De VRIESE, A.; SMITS, G. J. Influence of vasoactiveintestinal polypeptide and NG-nitro-Larginine methylester on cholinergic neurotransmission in the rat glandular stomach. Eur. J. Pharmacol. v. 221, p. 235-242, 1992.

$\mathrm{LI}, \mathrm{P}$. L. The intramural nervous system of the small intestine with special reference to the innervation of the inner subdivison of its circular muscle. J. Anat. v. 74, p. 348$359,1940$.

MAIFRINO, L. B. Aspectos morfológicos, histoquímicos e imunohistoquímicos do plexo mientérico do colo do camundongo "swiss" (Mus musculus) na fase 
da infecção por Trypanosoma cruzi (Cepa Y). São Paulo, 1996. (Tese de Doutorado - Escola Paulista de Medicina.

MOLINARI, S. L.; PEREIA, M. S.; SOUZA, R. R.; MIRANDA NETO, M. H. Estudo Morfológico do plexo mientérico do estômago glandular do pato (Anas $s p$ ). Unimar v. 16, n.2, p. 419-426, 1994.

MOLINARI, S. L.; FERNANDES, C. A.; SANT'ANA, D. M. G.; MIRANDA-NETO, M. $\mathrm{H}$. NADH-diaphorase positive myenteric neurons of the aglandular region of the stomach of rats (Rattus norvegicus) subjected to desnutrition. Rev. Chil. Anat. v. 20, p. 19-23, 2002.

MOLINARI, S. L.; GALVANINI, P. A.; PEREIRA, M. A. S.; FURLAN, M. M. D. P.; MIRANDA-NETO, M. H. Profile of the cell body of NADH-diaphorase positive myenteric neurons from the stomach of rats (Rattus norvegicus) subjected alcoholism. Acta Sci. v. 26, n. 3,. P. 349-355, 2004.

MONTES, G.S.; JUNQUEIRA, L.C.U. The use of the picrosirius-polariation method for the study of the biopathology of collagen. Mem. Inst. Oswaldo Cruz, v. 86, n. 3, p. $1-11,1991$.

MOORE, F. A.; MOORE, E. E.; JONES, T. N.; McCRISJKY, B. L.; PETERSON V. M. TEN versus TNP following major abdominal trauma: reduced septic morbidity. $\mathbf{J}$ Traum. v. 216, p. 172-183, 1989.

OLIVEIRA, L. R.; MOLINARI, S. L.; PEREIRA, M. A. S.; MIRANDA-NETO, M. H.; SANT'ANA, D. M. G. Localização dos neurônios mioentéricos no estômago aglandular e glandular de ratos (Rattus norvegicus). Arq. Cienc. Saúde Unipar. v. 4, p. 215-220, 2000.

POTTEN, C.S. Regeneration in epithelial proliferative units as exemplified by small intestinal crypts. Ciba Found Symp. v. 1, n. 160, p. 54-71, 1991.

POTTEN,C.S.; BOOTH, C.; CHADWICK, C. A.; EVANS, G. S. A potent stimulator of small intestinal cell proliferation extracted by simple diffusion from intact irradiated intestine: in vitro studies. Grow. Fact. v. 10, n. 1, p.53-61, 1994.

POTTEN, C. S. Epithelial cell growth and differentiation. II. Intestinal apoptosis. Am. J. Physiol. v. 273, n. 2, p.G253-G257, 1997. 
RAMZY, P. I.; WOLF, S. E.; IRTUN, O.; HART, D. W.; THOMPSON, J. C.; HERNDON, D. N. Gut Epithelial Apoptosis after Severe Burn: Effects of Gut Hypoperfusion. J. Am. Coll. Surg. v. 190, p. 281-287, 2000.

ROSSI, L. A.; BRAGA, E. C. F.; BARRUFFINI, R.; CARVALHO, E. C. Childhood burn injuries: circumstances of occurences and their prevention in Ribeirão Preto, Brazil. Burns. v. 24, p. 416-419, 1998.

SAYEGH, A.; RITTER, R. C. Morphology and Distribution of Nitric Oxide Syntase, Neurokinin-1 receptor, Calretinin, Calbindin and Neurofilament-M- Imunoreative neurons in the Myenteric and Submucosal Plexuses of the Rat Small Intestine. The Anatomic. Rec. Part. v. 271A, p. 209-216, 2003.

SCHABADASH, A. Die Nerven des Magens der Katza. Z Zellforsch. v. 10, p. 254319, 1930a.

SCHABADASH. A. Intramurale Nervengeflechte des Darmrohrs. Z Zellforsch. v.10, p. $320-385,1930$ b

SCHWEINBURG, F.; SELIGMAN, A.; FINE, J. Transmural migration of intestinal bacteria. N. Engl. J. Med. v. 242, p. 747, 1950.

SORI, A. J.; RUSH, B. F.; LYSZ, T. W.; MACHIEDO, G. W. The gut as source of sepsis after hemorrhagic shock. Am. J. Surg. v. 155, p. 187-192, 1988.

STOHR, P. Mikroskopische Studien sur Innervation des Magen-Darmkanales Z. Zellfor. Mickr. Anat. v. 12, p. 66-154, 1930.

SUN, W. M.; DORAN, S.; JONES, K. L.; OOI, E.; BOECKXTAENS, G.; HEBBARD, G. S.; LINGENFELSER, T.; MORLEY, J. E.; DENT, J.; HOROWTZ, M. Effects of nitroglycerin on liquid gastric emptying and antropyloroduodenal motility. Am. J. Physiol. v. 275, p. G1173-G1178, 1998.

VAREDI, M.; GREELEY, G. H. Jr.; HERNDON, D. N.; ENGLANDER, E. W. A thermal injury-induced circulation factor(s) compromises intestinal cel morphology, proliferation and migration. Am. J. Phisiol. v. 277, n.1, p. G175-G182, 1999.

VAREDI, M.; CHINERY, R.; GREELEY, G. H.; HERDON, D. N.; ENGLANDER, W. Thermal injury effects on intestinal crypt cell proliferation and death are cell position dependent. Am. J. Physiol. Gastrointest. Liver. Physiol. v. 280, p. G157-G163, 2000. 
WALKER, H. L.; MASON, J. D. A. A Standard animal burn. J. Trauma. v. 8, p. 10491051, 1968.

WESSER, T.; O'BIAIN, D. S.; PURI, P. Notable postnatal alterations in the myenteric plexus of normal human bowel. Gut. v. 44, p. 666-674, 1999.

WILMORE, D. W.; SMITH, R. J.; O'DWYER, S. T.; JACOBS, D. O.; ZIEGLER, T. R.; WANG X. D. The gut a central organ after surgical stress. Surg. v. 104, p. 917-923, 1988.

WOLF, S. The psyche and the stomach. Gastrenterol. v. 80, p. 605-614, 1981.

YOUNG, H M.; FURNESS, J. B.; SEWELL, P.; BURCHER, E. F.; KANDIAH, C. J. Total numbers of neurons in myenteric ganglia of guinea pig small intestine. Cell and Tissue Res. v. 272, p. 197-200, 1993. 